
\title{
Research S Surare \\ Application of Extended Finite Element Method in Fracture Propagation Simulation of Plastic Formation
}

\section{Yafei Hu ( 540924782@qq.com )}

PetroChina Research Institute of Petroleum Exploration \& Development, China Junshi Li

Petrochina Consulting Center, China

\section{Zhiying WU}

Reservoir Reconstruction Department of SRIPE, China

\section{Jianfeng Hou}

PetroChina Research Institute of Petroleum Exploration \& Development, China

\section{Research Article}

Keywords: Elastic-plastic model, Cohesive element method, Fracture parameter, Injection pressure, Plastic deformation, Friction angle, Dilation angle

Posted Date: January 14th, 2021

DOl: https://doi.org/10.21203/rs.3.rs-143248/v1

License: (c) (i) This work is licensed under a Creative Commons Attribution 4.0 International License. Read Full License 


\title{
Application of Extended Finite Element Method in Fracture
} Propagation Simulation of Plastic Formation

\author{
Yafei $\mathrm{Hu}^{1}$, Junshi $\mathrm{Li}^{2}$, Zhiying $\mathrm{Wu}^{3}$, Jianfeng $\mathrm{Hou}^{1}$ \\ ${ }^{1}$ PetroChina Research Institute of Petroleum Exploration \& Development, Beijing 100083, China \\ ${ }^{2}$ Petrochina Consulting Center, Beijing 100120, China \\ ${ }^{3}$ Reservoir Reconstruction Department of SRIPE, Beijing 100101, China \\ ${ }^{*}$ Correspondence to $540924782 @ q q . c o m$
}

\begin{abstract}
Current hydraulic fracture models are mainly based on elastic theories, which fail to give accurate prediction of fracture parameters in plasticity formation. This paper proposed a fluid-solid coupling model for fracture propagation in elastoplastic formations. The rock plastic deformation in the model satisfied the MohrCoulomb yield criterion and plastic strain increment theory. The coupled model is solved by using extended finiteelement method(XFEM) and the cohesive zone method (CZM). The accuracy of the model is verified by comparing the calculated results with existing models. The influences of stress difference, friction angle and dilation angle on fracture shape (length, width), injection pressure, plastic deformation, induced stress and pore pressure are investigated. The results indicate that compared with elastic formation, fracture shape in elastoplastic formation is wider and shorter and fracture propagation is more difficult with greater breakdown pressure and extending pressure. Plastic deformation also cause blunt fracture tip. High stress difference or low friction angle formations tend to occur large plastic deformation area and form wide and short fracture. Compared with friction angle, dilation angle is less sensitive to plastic deformation and fracture parameters and geometry. For the formation with high stress difference and friction angle, plasticity effects on fracture propagation should not be ignored.
\end{abstract}

Keywords: Elastic-plastic model; Cohesive element method; Fracture parameter; Injection pressure; Plastic deformation; Friction angle; Dilation angle

\section{Introduction}

With the increasing energy consumption, efficient development of oil and gas resources has become the focus of attention. Hydraulic fracturing (HF), as a widely used technology, has become increasingly important in oil and gas stimulation (Hu et al, 2019; Zhao et al, 2019). Studying fracture propagation mechanism has a great significance for fracture parameter (with, length, height) optimization. The classical fracture propagation models treated formation as an elastic medium without considering the plasticity effects and fluid-solid coupling. (Perkins and Kern, 1961; Geertsma and Klerk, 1969; Nordgren, 1972; Saouma et al, 1987; Dean and Schmidt, 2009; DahiTaleghani and Olson JE, 2011; Leonhart and Meschke, 2011). However, plastic failure usually occurs in soft rocks of high temperature and pressure formation and unconsolidated formation during fracturing (Brünig, 1999; Abu Al-Rub and Voyiadjis, 2003; Bohloli and de Pater, 2006). Various experiment have been conducted on fracture propagation in soft rocks. The results indicate that with the increase of confining pressure, the rock property gradually appear plastic character, which has great influence on fracture pressure and fracture shape (Sone and Zoback, 2011; Busetti et al, 2012a, 2012b; Wang, 2015; Shojaei et al, 2016). Complex fracture and fluid lag near the fracture was also observed in soft rock during fracturing. Initiation pressure and fracture width was also affected by the confining stresses in unconsolidated formation (Van Dam et al, 2002; De Pater et al, 2007; Golovin et al, 2010; Germanovich et al, 2012; Omori et al, 2013). Owing to rock plasticity and strong fluid-solid coupling, traditional fracture propagation models fail to accurately 
predict the fracture parameters in soft formation.

Previous studies on the effect of plasticity in HF were just based on the static fracture and constant injection pressure in fracture without considering the coupling between the pressure diffusion and rock deformation. Papanastasiou (Papanastasiou, 1997, 1999, 2012) proposed that plastic yielding was affected by rock dilation, stress difference and the cohesive zone, and utilized the Mohr-Coulomb criterion to study the effect of pore pressure and permeability on fracture parameters without considering the fluid-solid coupling in porous formation. Zaki (Zaki et al, 2004) used the cam-clay model to assess the influence of rock plasticity on fracture volumes based on the simple models that would rely in using lower modulus or higher fracture toughness to account for plasticity. Wang (Wang et al, 2016) proposed the poroelastic and poroplastic HF model in brittle and ductile formations. Liu (Liu et al., 2019) established fracture propagation model based on the Drucker-Prager yield criterion and the associated flow law. Lin (Lin et al, 2018) investigated the effects of young's model, Poisson's ratio and injection rate on fracture propagation based on the modified cam-clay model. However, the influence of rock plasticity on the pore pressure and induced stress distribution based on fluid-solid coupling and the effects of rock friction angle, dilation angle and principal stress difference on fracture propagation were not considered in the above studies. Therefore, it is necessary to establish a fluid-solid coupling model for fracture propagation in elastoplastic formations.

In this study, a fluid-solid coupling elastoplasticity HF model is proposed. The rock plastic deformation conforms to the Mohr-Coulomb criterion and plastic strain increment theory. Fluid flows within the fracture follows the mass conservation law. The fracture propagation criterion is based on the traction/separation law of cohesive element. By combining the extended finite-element method (XFEM) and the cohesive zone method (CZM), Abaqus 6.14 software has been utilized to simulate fracture initiation and growth in elastoplastic formation. The simulation results are also compared with existing fracture expansion models. Meanwhile, the influences of principal stress difference, friction angle and dilation angle on fracture length, width, injection pressure, plastic deformation, pore pressure and induced stress are further investigated.

\section{Mathematical model}

Fracture propagation involves rock deformation and failure, fluid flowing in fracture and formation, the dynamic variation of pore pressure and induced stress, which is a very complex process, involving multiple coexisting and interdependent sub-processes ( $\mathrm{Wu}, 2014)$. In addition, formation heterogeneity and plasticity make modeling more complex. In order to simplify the process of crack propagation, the following assumptions are made:

1) Formation is a homogeneous, porous elastic-plastic rock medium;

2) Fracture extending without proppant transport;

3) Fluid flows within the fracture existing fluid leakoff;

4) Fluid flows through the formation in accordance with the Darcy law;

5) Formation temperature is constant during fluid injection;

\subsection{Fluid-solid coupling equation of rock deformation}

Based on the above assumptions, rock deformation conforms to pore-elastoplastic theory. According to the stress balance equation, the stress equilibrium, strain displacement, and strainstress equations can be written as follows (Ma et al, 2016): 


$$
\left\{\begin{array}{l}
d \sigma_{i j, j}+d f_{i}=0 \\
d \varepsilon_{i j}=\frac{1}{2}\left(d u_{i, j}+d u_{j, i}\right) \\
d \sigma_{i j}=D_{i j k l}^{e p} d \varepsilon_{k l}
\end{array}\right.
$$

Where $d \sigma_{i j}$ is the stress increment, $d \varepsilon_{i j}$ is the strain increment, $d u_{i, j}$ is the medium displacement increment, $d f_{i}$ is the body force increment, $D_{i j k l}^{e p}$ is elastic-plastic coefficient matrix.

The displacement and stress at the outer boundary and fluid pressure at the fracture surface are

$$
\begin{cases}d u=d u^{*}, & \text { on } \Gamma_{u} \\ d \sigma \bullet n=d t^{*}, & \text { on } \Gamma_{t} \\ d n^{T}(\sigma \bullet n)=-d p, & \text { on } \Gamma_{c r}\end{cases}
$$

where $\Gamma_{u}, \Gamma_{t}$, and $\Gamma_{c r}$ are the displacement boundary condition, stress boundary condition, and fracture pressure boundary condition, respectively; $u^{*}$ and $t^{*}$ are the corresponding displacement and stress increment on the boundary; and $d p$ is fluid pressure increment on the fracture.

\subsection{The elastic-plastic increment constitutive model}

When the rock begins to occur plastic failure, the strain increment of the rock is composed of elastic strain increment and plastic strain:

$$
d \varepsilon_{i j}=d \varepsilon_{i j}^{e}+d \varepsilon_{i j}^{p}
$$

The elastic strain increment $d \varepsilon_{i j}^{e}$ and the stress increment $d \sigma_{i j}$ satisfy the Hooke's law:

$$
d \sigma_{i j}=D_{i j k l}^{e} d \varepsilon_{k l}^{e}
$$

The plastic strain increment follows the flow rule, which is defined as (Vermeer and Borst, 1984):

$$
d \varepsilon_{i j}^{p}=\lambda \frac{\partial F}{\partial \sigma_{i j}}
$$

In the process of plastic deformation, the yield surface of the rock is a function of strengthening parameters, plastic strain and stress:

$$
F=F\left(\sigma_{i j}, \varepsilon_{i j}^{p}, \kappa\right)
$$

$$
d F=\frac{\partial F}{\partial \sigma_{i j}} d \sigma_{i j}+\frac{\partial F}{\partial \kappa} d \kappa+\frac{\partial F}{\partial \varepsilon_{i j}^{p}} d \varepsilon_{i j}^{p}=0
$$

Where $\varepsilon_{i j}$ is the total strain; $\varepsilon_{l j}^{e}$ is the elastic strain; $\varepsilon_{l j}^{p}$ is the plastic strain; $\sigma_{i j}$ is the stress tensor; $D_{i j k}^{e}$ is the elastic constitutive tensor; $F$ is the load surface equation; $\kappa$ is the strengthening parameter of rock; $\lambda$ is a quantity related to the slope of the uniaxial curve of stress $\sigma$-plastic strain $\varepsilon^{p}$, which can be determined by yield criteria and strengthening theory.

The stress increment is obtained by substituting equation (4) into (3).

$$
d \sigma_{i j}=D_{i j k l}^{e}\left(d \varepsilon_{k l}-d \varepsilon_{k l}^{p}\right)
$$

Multiplying both sides of equation (8) by $\partial F / \partial \sigma_{i j}$ and substituting it into equation (7): 


$$
\frac{\partial F}{\partial \sigma_{i j}} D_{i j k l}^{e}\left(d \varepsilon_{k l}-d \varepsilon_{k l}^{p}\right)=-\frac{\partial F}{\partial \kappa} d \kappa-\frac{\partial F}{\partial \varepsilon_{i j}^{p}} d \varepsilon_{i j}^{p}
$$

The hardening parameter is a function of the equivalent plastic strain and temperature, which is determined as:

$$
\begin{aligned}
& \frac{\partial F}{\partial \kappa} d \kappa=\frac{\partial F}{\partial \kappa}\left(\frac{\partial \kappa}{\partial \bar{\varepsilon}^{p}} d \bar{\varepsilon}^{p}+\frac{\partial \kappa}{\partial T} d T\right)=\frac{\partial F}{\partial \kappa}\left(\frac{\partial \kappa}{\partial \bar{\varepsilon}^{p}}+\frac{\partial \kappa}{\partial T} \frac{\partial T}{\partial \bar{\varepsilon}^{p}}\right) d \bar{\varepsilon}^{p} \\
& =\frac{\partial F}{\partial \kappa}\left(\frac{\partial \kappa}{\partial \bar{\varepsilon}^{-p}}+\frac{\partial \kappa}{\partial T} \frac{\partial T}{\partial \bar{\varepsilon}^{p}}\right) \frac{d \bar{\varepsilon}^{p}}{d \bar{\varepsilon}_{i j}^{-P}} d \bar{\varepsilon}_{i j}^{P}
\end{aligned}
$$

The equivalent plastic strain increment is defined as:

$$
\begin{aligned}
& d \bar{\varepsilon}^{p}=\left[\frac{2}{3} d \varepsilon_{i j}^{P} d \varepsilon_{i j}^{P}\right]^{1 / 2}=\frac{\sqrt{2}}{3}\left\{\left(d \varepsilon_{x}^{P}-d \varepsilon_{y}^{P}\right)^{2}+\left(d \varepsilon_{y}^{P}-d \varepsilon_{z}^{P}\right)^{2}+\left(d \varepsilon_{z}^{P}-d \varepsilon_{x}^{P}\right)^{2}\right. \\
& \left.+\frac{3}{2}\left[\left(\mathrm{~d} \gamma_{x y}^{P}\right)^{2}+\left(\mathrm{d} \gamma_{y z}^{P}\right)^{2}+\left(\mathrm{d} \gamma_{x z}^{P}\right)^{2}\right]\right\}^{1 / 2}
\end{aligned}
$$

Where $\bar{\varepsilon}^{P}$ is the equivalent plastic strain; $T$ is temperature; $\varepsilon_{x}^{p} 、 \varepsilon_{y}^{p} 、 \varepsilon_{z}^{p}$ are the plastic strain on the $\mathrm{x}, \mathrm{y}$ and $\mathrm{z}$ axis respectively; $\gamma_{x y}^{p} 、 \gamma_{y z}^{p} 、 \gamma_{x z}^{p}$ is the shear stress component.

Substituting equation (10) and (5) into equation (9)

$$
\lambda=\frac{\frac{\partial F}{\partial \sigma_{i j}} D_{i j k l}^{e} d \varepsilon_{k l}}{A}
$$

Where

$$
A=\left[\frac{\partial F}{\partial \sigma_{i j}} D_{i j k l}^{e}-\frac{\partial F}{\partial \kappa}\left(\frac{\partial \kappa}{\partial \bar{\varepsilon}^{p}}+\frac{\partial \kappa}{\partial T} \frac{\partial T}{\partial \bar{\varepsilon}^{p}}\right) \frac{d \bar{\varepsilon}^{p}}{d \bar{\varepsilon}_{i j}^{-P}}-\frac{\partial F}{\partial \varepsilon_{k l}^{p}}\right] \frac{\partial F}{\partial \sigma_{k l}}
$$

Substituting equation (12) and (13) into equation (3) and then substituting equation (5) into equation (8), the elastic -plastic matrix can be obtained.

$$
d \sigma_{i j}=D_{i j k l}^{e p} d \varepsilon_{k l}
$$

$$
D_{i j k l}^{e p}=D_{i j k l}^{e}-\frac{D_{i j k l}^{e}\left[\frac{\partial F}{\partial \sigma_{p q}} \frac{\partial F}{\partial \sigma_{r s}} D_{p q r s}^{e}\right]}{A}
$$

\subsection{Plastic yield criteria for rocks}

Rock deformation obeys the Mohr-Coulomb yield criterion, and we stipulates that the tensile stress is positive and the compressive stress is negative:

$$
\tau=c-\sigma \tan \varphi(16)
$$

According to the geometry of the mole circle, shear stress $\tau$ and normal stress $\sigma$ can be expressed as following: 


$$
\left\{\begin{array}{l}
\tau=\frac{\sigma_{1}-\sigma_{3}}{2} \cos \varphi \\
\sigma=\frac{\sigma_{1}+\sigma_{3}}{2}+\frac{\sigma_{1}-\sigma_{3}}{2} \sin \varphi
\end{array}\right.
$$

Where $\tau$ is the shear stress; $\sigma$ is the normal stress; $\varphi$ is the friction degree; $\sigma_{l}$ and $\sigma_{3}$ are the maximum and minimum principal stresses, respectively; $\sigma_{2}$ are the Intermediate principal stress; Substitute equation (17) into equation (16), we have:

$$
\frac{\sigma_{1}-\sigma_{3}}{2} \cos \varphi=c-\left[\frac{\sigma_{1}+\sigma_{3}}{2}+\frac{\sigma_{1}-\sigma_{3}}{2} \sin \varphi\right] \tan \varphi
$$

Principal stress and principal deviatoric stress satisfy the following equation:

$$
\left\{\begin{array}{l}
\sigma_{1}=\frac{2}{\sqrt{3}} \sqrt{\mathrm{J}_{2}} \cos \Theta+\frac{1}{3} I_{1} \\
\sigma_{2}=\frac{2}{\sqrt{3}} \sqrt{\mathrm{J}_{2}} \cos \left(\frac{2 \pi}{3}-\Theta\right)+\frac{1}{3} I_{1} \\
\sigma_{3}=\frac{2}{\sqrt{3}} \sqrt{\mathrm{J}_{2}} \cos \left(\frac{2 \pi}{3}+\Theta\right)+\frac{1}{3} I_{1}
\end{array}\right.
$$

Where $\sigma_{1}$ and $\sigma_{3}$ are the maximum and minimum principal stresses, respectively; $\sigma_{2}$ are the Intermediate principal stress; $I_{1}$ is the first invariant of stress tensor; $J_{2}$ is the second invariant of deviatoric stress; $\Theta$ is the deviatoric polar angle.

Substitute equation (19) into equation (18):

$$
\mathrm{F}=\frac{1}{3} I_{1} \sin \varphi+\sqrt{\mathrm{J}_{2}} \sin \left(\Theta+\frac{\pi}{3}\right)+\frac{\sqrt{\mathrm{J}_{2}}}{\sqrt{3}} \cos \left(\Theta+\frac{\pi}{3}\right) \sin \varphi-c \cos \varphi=0
$$

Equivalent compressive stress $p$, Mises equivalent stress $q$, the first invariant of stress tensor $I_{l}$ and the second invariant of deviatoric stress $J_{2}$ satisfy the following equation:

$$
\left\{\begin{array}{l}
p=-\frac{1}{3} \operatorname{trace}(\sigma)==-\frac{I_{1}}{3} \\
q=\sqrt{\frac{3}{2} s_{i j} s_{i j}}=\sqrt{3 \mathrm{~J}_{2}} \\
\cos (3 \Theta)=\frac{r^{3}}{q^{3}}
\end{array}\right.
$$

Where $\mathrm{p}$ is the equivalent pressure stress; $\mathrm{q}$ is the Mises equivalent stress; $r$ is the third invariant of deviatoric stress; $s$ is the deviatoric stress.

Substitute equation (21) into equation (20):

$$
F=f(p, q, \Theta)=R_{m c} q-p \tan \varphi-c=0
$$

Where

$$
R_{m c}=\frac{1}{\sqrt{3} \cos \varphi} \sin \left(\Theta+\frac{\pi}{3}\right)+\frac{1}{3} \cos \left(\Theta+\frac{\pi}{3}\right) \tan \varphi
$$


In the case of equation (23), there will be sharp angles on the yield surface, leading to not unique plastic flow direction, which leads to tedious calculation and slow convergence. In order to solve this problem, Menetrey and Willam (Menetrey and Willam, 1995) proposed a continuous smooth elliptic function as a plastic potential surface.

$$
G=\sqrt{\left(\varepsilon \mathrm{c}_{0} \tan \psi\right)^{2}+\left(R_{m w} q\right)^{2}}-p \tan \psi
$$

Where

$$
R_{m w}=\frac{4\left(1-e^{2}\right) \cos ^{2} \Theta+(2 e-1)^{2}}{2\left(1-e^{2}\right) \cos \Theta+(2 e-1) \sqrt{4\left(1-e^{2}\right) \cos ^{2} \Theta+5 e^{2}-4 e}} \frac{3-\sin \varphi}{6 \cos \varphi}
$$

$$
e=\frac{3-\sin \varphi}{3+\sin \varphi}
$$

Where $\psi$ is the dilation angle measured in the $\mathrm{p}-\mathrm{R}_{\mathrm{mw}} \mathrm{q}$ plane at high confining pressure and can depend on temperature and predefined field variables; $\mathrm{c} 0$ is the initial cohesion yield stress; $\varepsilon$ is the eccentricity ratio, here is assumed to be 0.1 ; e is the "out of roundedness" of the deviatoric section in terms of the ratio between the shear stress along the extension meridian and the shear stress along the compression meridional.

\subsection{Fluid flow in fracture and formation}

Once the fracture is formed, fluid will flow into the fracture at once, fluid flow in the fracture follows the mass conservation law (Yao, 2012):

$$
\frac{\partial w}{\partial t}+\frac{\partial q_{t}}{\partial s}+v_{t}+v_{b}=0
$$

Where $q_{t}$ is the injection flow rate, $w$ is the fracture width, $s$ is the fracture length, $t$ is injection time, $v_{t}$ and $v_{b}$ are the fracturing fluid leakoff rate through the top and bottom fracture surfaces, respectively.

Both tangential flow along and normal flow across the fracture surfaces can be calculated using the Poiseuille equation (Boone and Ingraffea, 1990; Chen Z, Bunger et al, 2009):

$$
q_{t}=\frac{w^{3}}{12 \mu} \frac{\partial p}{\partial s}
$$

Where $\mu$ is the fluid viscosity, $\mathrm{p}$ is the fluid pressure.

Fluid leakoff rate is mainly affected by pressure and leakoff coefficient, which satisfy the following equation (Elguedj, 2006; Zielonka et al, 2014):

$$
\left\{\begin{array}{l}
v_{t}=c_{t}\left(p-p_{t o p}\right) \\
v_{b}=c_{t}\left(p-p_{b o t}\right)
\end{array}\right.
$$

Where $c_{t}$ is the fluid leakoff coefficients, $p_{\text {top }}$ and $p_{\text {bot }}$ are pressure in the top and bottom fracture surface, respectively.

When the fluid leaks off from the fracture, it will flows through the formation in accordance with the Darcy law. The mass conservation equation is expressed as:

$$
\nabla\left(\frac{\rho_{w} k_{w}}{b_{w} \mu_{w}} \nabla p_{w}\right)+q_{w}=\frac{\partial}{\partial t}\left(\frac{\phi \rho_{w} s_{w}}{b_{w}}\right)
$$


Where $\rho_{\mathrm{w}}$ is the water permeability; $k_{w}$ is the water permeability; $p_{w}$ is water pressure in formation; $b_{w}$ is the water compression coefficient; $\mu_{w}$ is the water viscosity; $q_{w}$ are the leakoff fluid; $S_{w}$ is the water saturation; $\phi$ is the effective porosity.

\subsection{Cohesive crack model}

The singularity of the fracture tip stress field will affect the convergence of the calculation of the model. In order to solve this problem, CZM is adopted to simulate the initiation and propatation of fractures. This method is implemented by embedding an artificially predefined path of cohesive element into the formation. The cohesive element glues two conjugated cohesive surfaces of the reservoir pressure/displacement element. The failure of these element obeys the traction/separation law in the vertical or shear direction (Tvergaard and Hutchinson, 1992; Camacho and Ortiz, 1996). When the cohesive element is completely destroyed, the two bound cohesive surfaces are separated and hydraulic fracture is generated. When the maximum nominal stress criterion is adopted for rock failure, initiation propagation occurs as the maximum nominal stress ratio reaches a critical value (Nguyen et al, 2017; Sobhaniaragh et al, 2018a, 2018b):

$$
f_{c}=\max \left\{\frac{\left\langle T_{n}\right\rangle}{T_{n}^{0}}, \frac{T_{s}}{T_{s}^{0}}\right\}
$$

$$
1 \leq f_{c} \leq 1+f_{t}
$$

Where $\delta_{n}, \delta_{s}$ are, respectively the normal and tangential displacement jump vector; $\delta_{e q}$ are effective displacement; $T_{n}^{0}, T_{s}^{0}$ are, respectively the normal and tangential stress component of the stress element under a linear elastic condition; $<>$ denotes the Macaulay bracket; $f_{c}$ is a parameter evaluating the fracture failure, $f_{t}$ is assured to be 0.05 ;

The fracture damage evolution is determined by damage variables, and the expressions of damage effects on the normal and tangential stress components of the element can be obtained as (Zhu et al, 2015; Sobhaniaragh et al, 2018a, 2018b)

$$
T_{n}= \begin{cases}(1-d) T_{n}^{0}, & T_{n}^{0} \geq 0 \\ T_{n}^{0}, & T_{n}^{0}<0\end{cases}
$$

$$
T_{s}=(1-d) T_{s}^{0}
$$

Where $d$ is the scalar damage variable between fractures, $0<d<1 ; T_{n}, T_{s}$ are, respectively, the values of the normal stress component and the tangential stress component of the traction/separation model.

When the critical fracture energy of rock material along the first and second shear directions are similar, the damage evolution during fracture propagation can also be determined by the Benzeggagh-Kenane fracture criterion (Benzeggagh and Kenane, 1996). The combined energy dissipated by failure $G_{c}$ is defined as

$$
G^{\mathrm{c}}=G_{\mathrm{I}}^{c}+\left(G_{\mathrm{II}}^{c}-G_{\mathrm{I}}^{c}\right)\left(\frac{G_{\mathrm{II}}}{G_{\mathrm{I}}+G_{\mathrm{II}}}\right)^{\eta}
$$

where $G_{c}$ is the critical fracture energy release rate, $G_{I}^{c}$ and $G_{I I}^{c}$ are the normal and first shear direction fracture toughness values, $G_{I}$ and $G_{I I}$ are the normal and shear direction fracture energy 


\section{3、 Model verification}

In order to simulate HF in elastic-plastic formation, the size of geological model is set as $50 \mathrm{~m}$ x $50 \mathrm{~m}$ with a cohesive element embedded in the central of the model. The injection point is in the center of the cohesive zone. The minimum principal stress is in y direction. All the external boundary displacement are fixed in normal directions. The geological model is shown in figure 1 and the input parameters of simulation model is presented in table 1. The simulation calculation process consists of two steps: geostatic step and HF step. The purpose of geostatic step is to balance the applying initial formation stress and fluid pressure. HF step is to simulate the change of fluid injection, rock deformation and fracture initiation and expansion during fracturing.

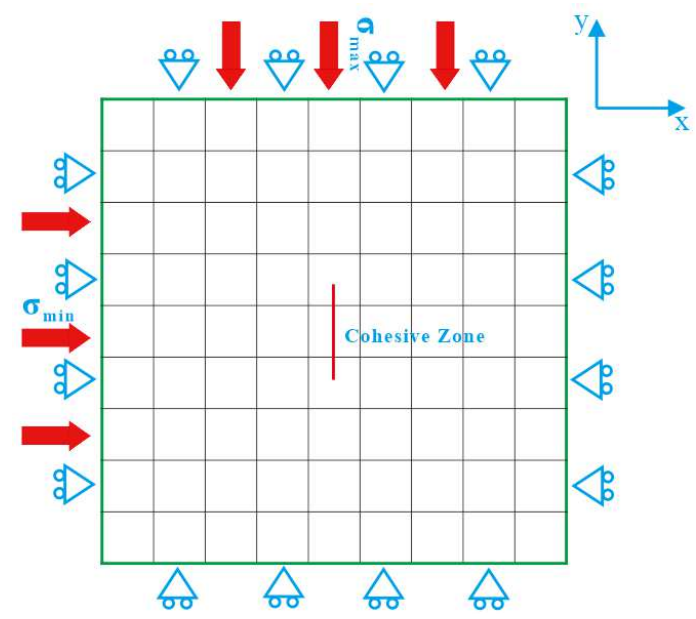

Figure.1. Geological model for hydraulic fracture simulation

Table. 1. Input parameters for hydraulic fracture model

\begin{tabular}{|c|c|}
\hline properties & Value \\
\hline Young modulus $(\mathrm{MPa})$ & 15000 \\
\hline Poisson ratio & 0.25 \\
\hline Material cohesion ( $\mathrm{MPa})$ & 1.5 \\
\hline Material friction angle $\left({ }^{\circ}\right)$ & 28 \\
\hline Material dilation angle $\left({ }^{\circ}\right)$ & 28 \\
\hline Formation permeability coefficients $(\mathrm{m} / \mathrm{s})$ & $1 \times 10^{-7}$ \\
\hline Maximum horizontal stress $\quad(\mathrm{MPa})$ & 20 \\
\hline Minimum horizontal stress $(\mathrm{MPa})$ & 15 \\
\hline Porosity & 0.1 \\
\hline Fluid viscosity（cp） & 1 \\
\hline Specific weight of fluid $\quad\left(\mathrm{KN} / \mathrm{m}^{3}\right)$ & 9.8 \\
\hline Initial pore pressure $\quad(\mathrm{MPa})$ & 0.1 \\
\hline Injection rate $(\mathrm{m} 3 / \mathrm{s})$ & $5 \times 10^{-3}$ \\
\hline Pressure dependent leak-off coefficient (m³/MPa.s) & $1 \times 10^{-14}$ \\
\hline Critical fracture energy $\left(\mathrm{KN} / \mathrm{m}^{3}\right)$ & 28 \\
\hline Damage initiation stress $\quad(\mathrm{MPa})$ & 0.32 \\
\hline
\end{tabular}


To verify the accuracy of the model, we compared the calculated results with the model of Papanastaiou. Papanastaiou's model is a simple fluid-solid couping model without considering fluid leak off and is solved numerically by a combined finite difference and finite element method. The change of injection pressure, fracture width and length and the equivalent plastic strain zone with time in elastic and elastic-plastic formation is also analyzed by the model. The calculated results are demonstrated in figure 1-4.

Fig.2a and Fig.3a exhibit that the injection pressure and fracture width at the wellbore in elastic-plastic formation is greater than that in elastic formation, resulting greater breakdown

253

254

255 pressure and propagation pressure in elastic-plastic formation, which is similar to results of Papanastaiou model shown in Fig.2b and Fig.3b. Moreover, in the early stage of fracture initiation, the change trend of injection pressure and fracture width at injection point are also in accordance with Papanastaiou model. Injection pressure in both models is first increased and then decreased to a constant value. Wellbore fracture width are also both gradually increasing with injection time.

Fig.4 presents that fracture in elastic-plastic formation is incline to be wider and shorter than elastic formation. Because plastic damage requires more energy and plastic deformation of rock also lead the fracture tip to be blunt, resulting fracture more difficult to extend. Fig.5 displays that the equivalent plastic strain area increases with injection time, and largest plastic strain appears near the fracture tip. The plastic deformation also cause rock compaction, resulting in the porosity and permeability loss around the fracture with less fluid leak off and higher injection pressure.

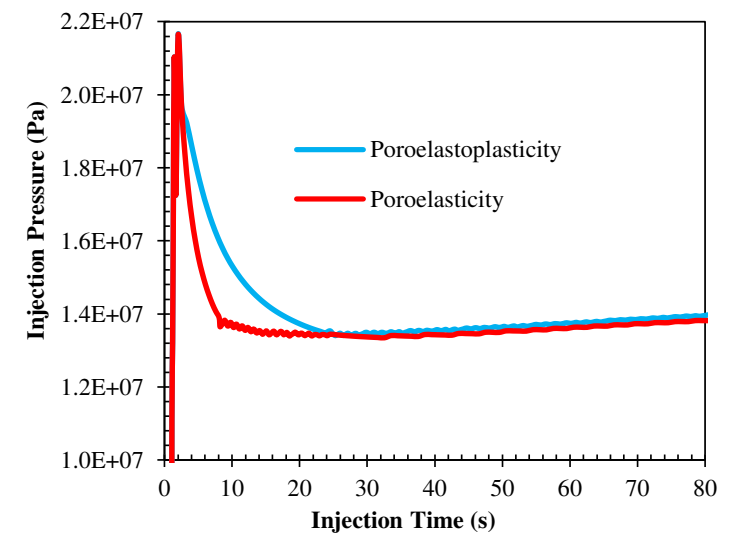

(a) Our model

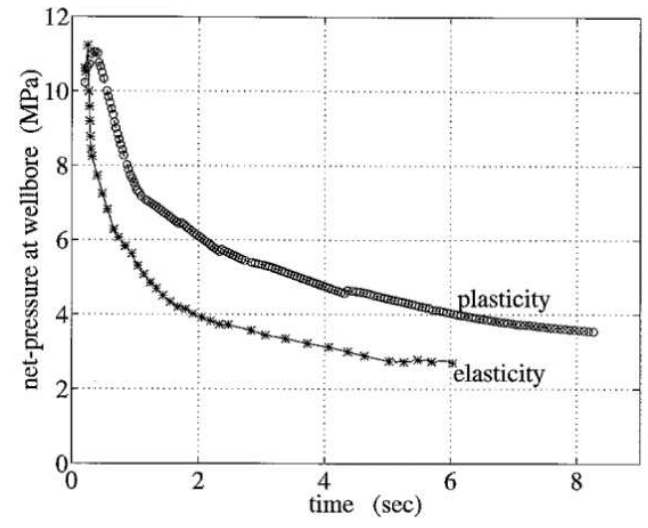

(b) Papanastaiou's model (Papanastasiou, 1997)

Fig.2. Comparison of injection pressure calculated by different models
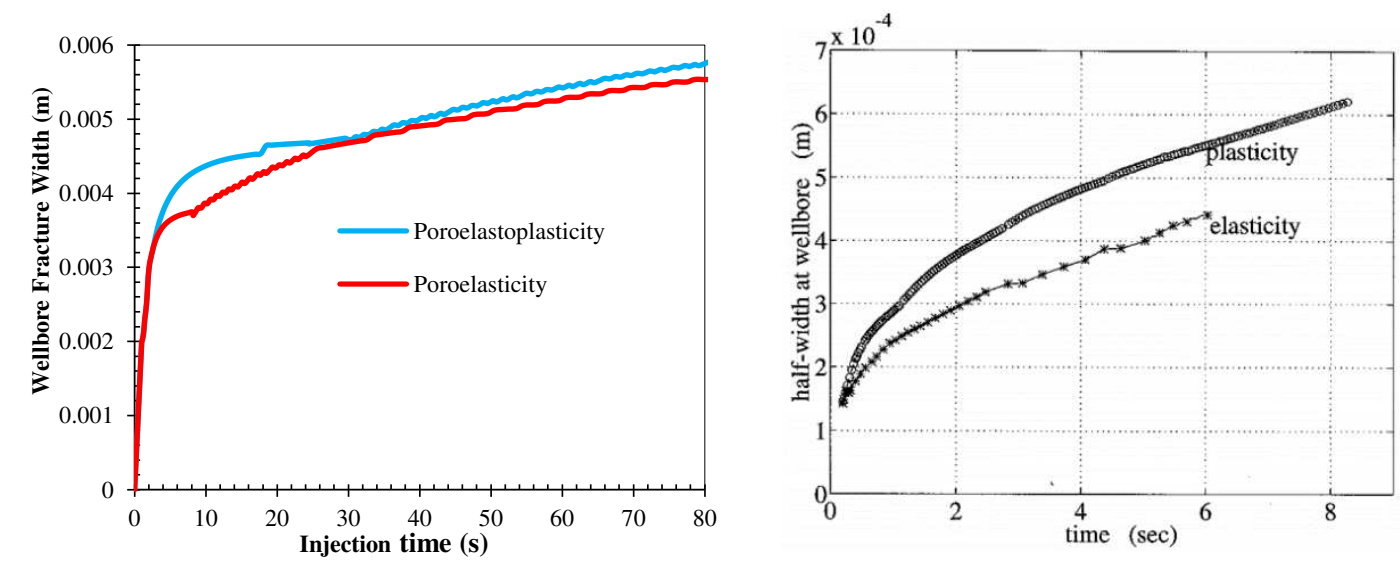

poroelastoplastic models

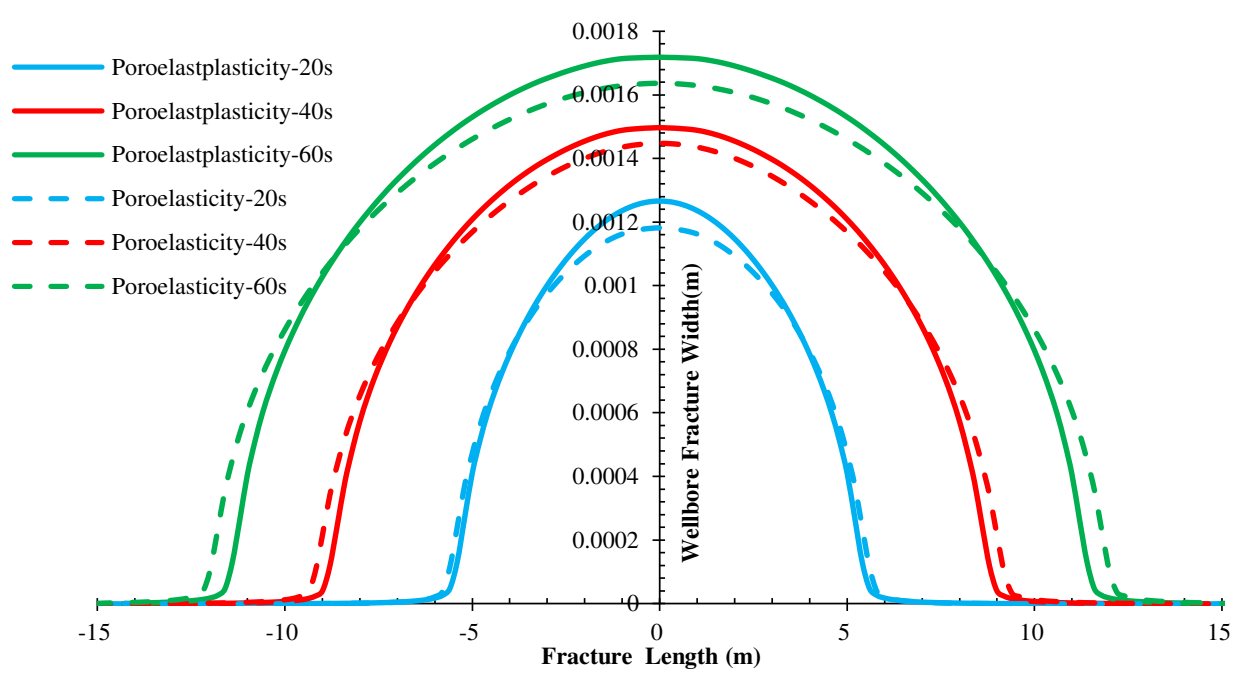

272

273

Fig.4. Comparison of fracture parameters with different time calculated by poroelastic and

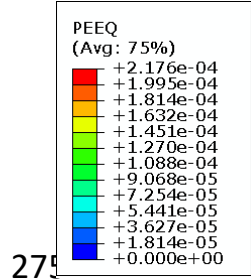

276

278

279

280

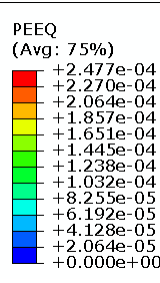
poroelastoplastic models

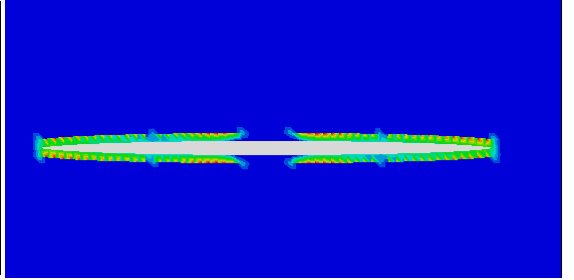

(a) Injection time at $20 \mathrm{~s}$

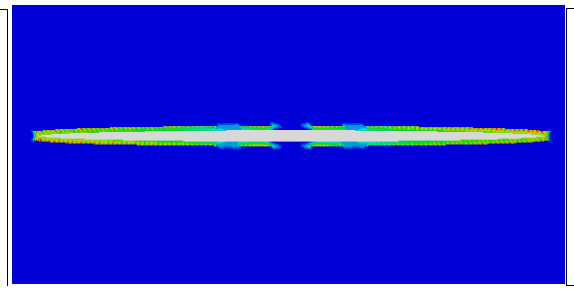

(c) Injection time at 60s

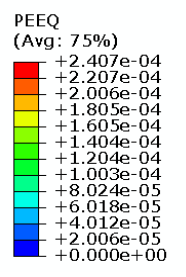

$+0.000 \mathrm{e}+00$

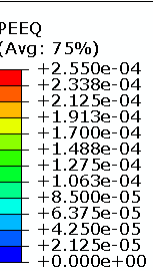

$+2.000+00$

Fig.5. Equivalent plastic strain zone of fracture varies with injection time

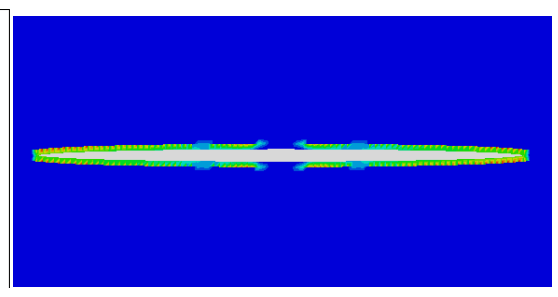

(b) Injection time at $40 \mathrm{~s}$

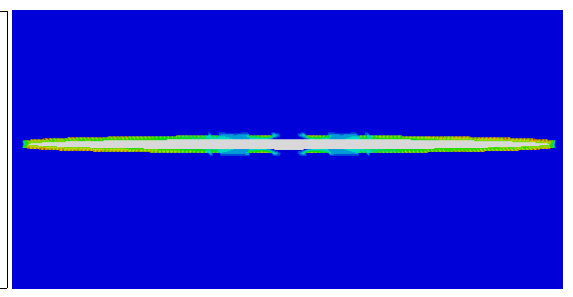

(d) Injection time at $80 \mathrm{~s}$

\section{4、 Numerical results and discussion}

\subsection{Effect of stress difference on fracture propagation}

The effects of horizontal principal stress differences on fracture width, length, injection pressure, fracture width at the wellbore, equivalent plastic strain of fracture, pore pressure and induced stress are simulated. It is assumed that the minimum horizontal principal stress is constant at $30 \mathrm{MPa}$, the horizontal principal stress difference is $5 \mathrm{MPa}, 8 \mathrm{MPa}$ and $10 \mathrm{MPa}$ respectively, the pore pressure of the formation is $20 \mathrm{MPa}$, the injection time is $80 \mathrm{~s}$, and the friction angle and dilation 
angle of the rock are both $15^{\circ}$. The calculation results are presented in figure 6-10.

Fig. 6 demonstrates that crack width increases and crack length decreases with the increasing stress difference. Fig. 7 indicates that the crack width at the wellbore and injection pressure increases with the increase of horizontal stress difference. Figure 8 displays that the area of equivalent plastic strain around the crack also increases with the increase of horizontal stress difference. Figure 9-10 present that pore pressure and induced stress in $\mathrm{x}$ direction surround the fracture also grows with the increasing stress difference. Because high stress difference is easy to generate large plastic zones, and rock compaction caused by the plastic deformation around the fracture leads to a decrease in porosity and permeability, which in turn makes it difficult for the fracturing fluid to flow into the formation, resulting greater pore pressure near the fracture surface. Meanwhile, the induced stress on the fracture surface also makes crack difficult to extent, owing to plastic effect. Therefore, plastic formations with high horizontal stress difference is benefit to form wide and short crack.

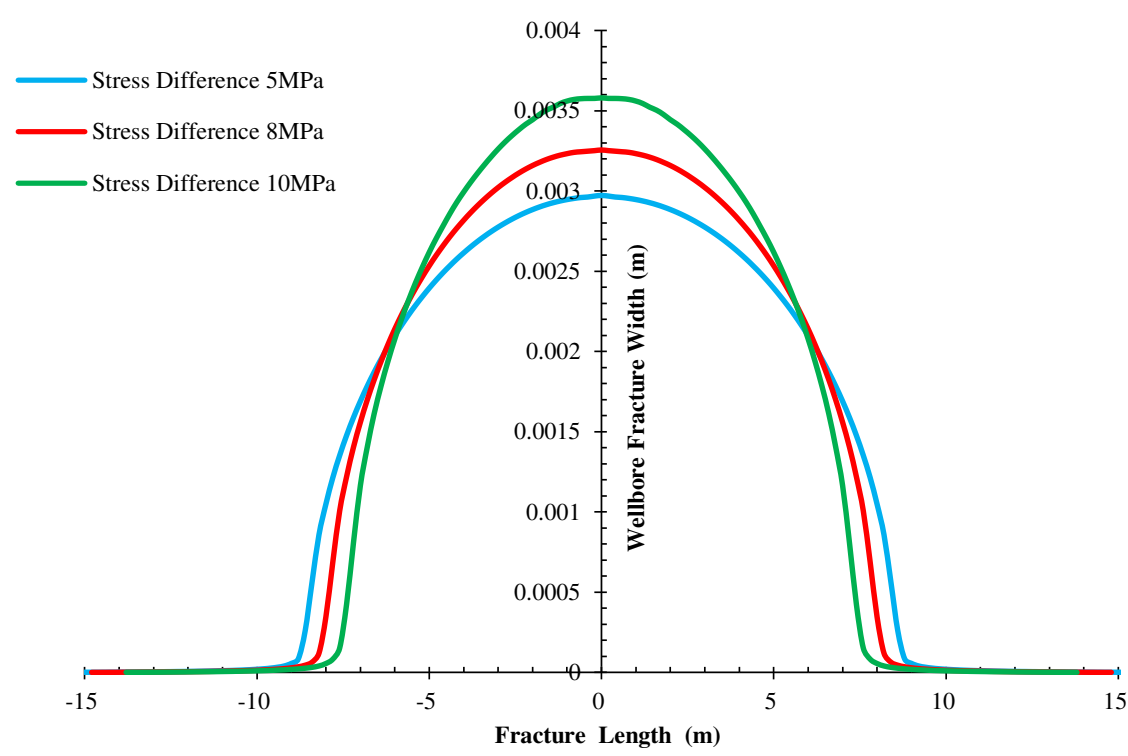

Fig.6. Effect of stress difference on fracture width and length 

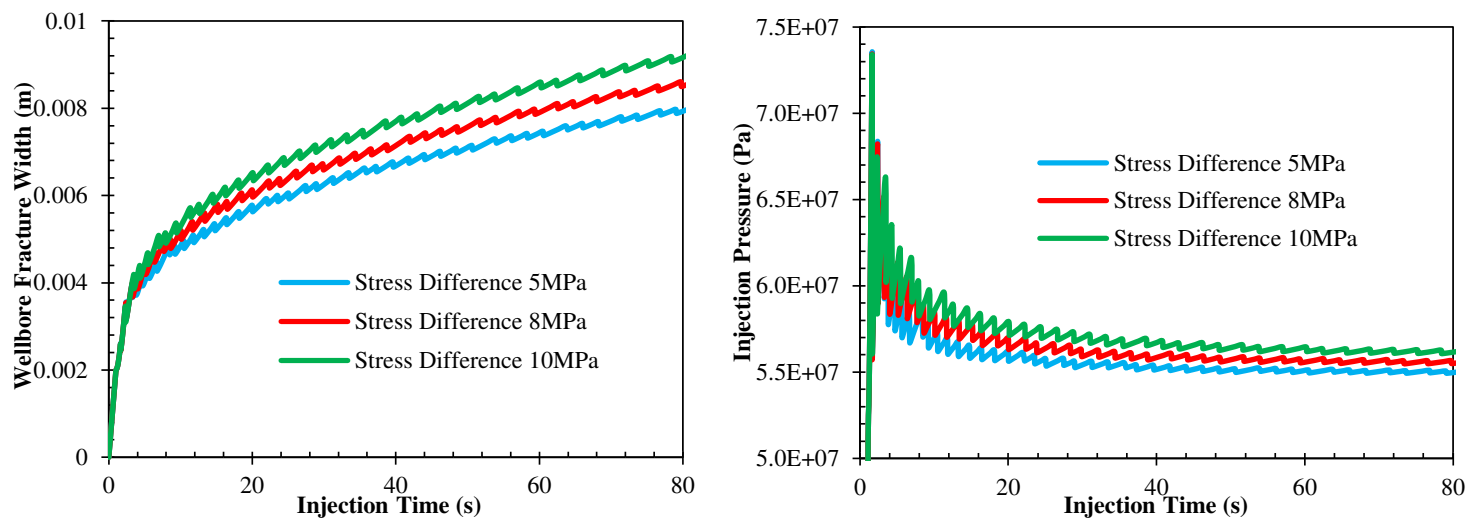

Fig.7. Effect of stress difference on wellbore fracture width and injection pressure

306
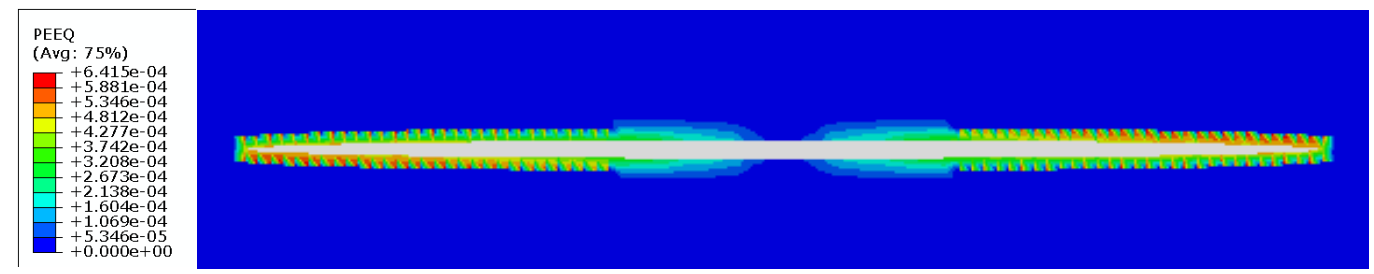

(a) Stress difference $5 \mathrm{MPa}$
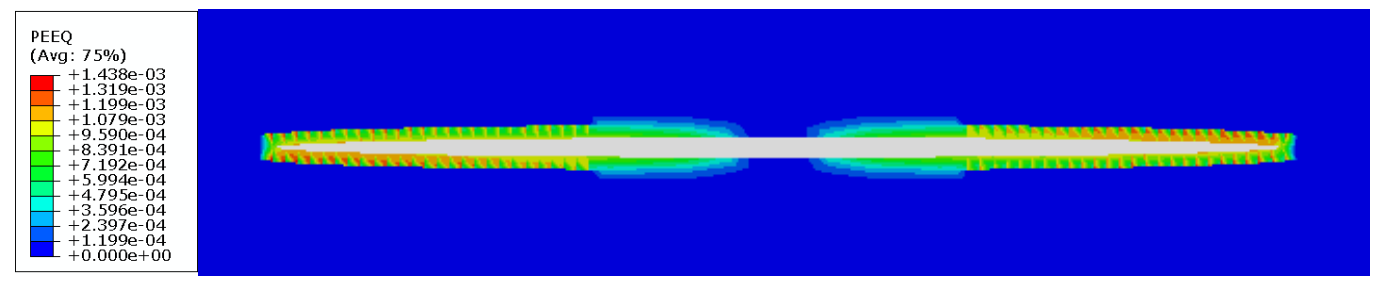

(b) Stress difference 8MPa

(c) Stress difference 10MPa

Fig.8. Effect of stress difference on equivalent plastic strain zone of fracture

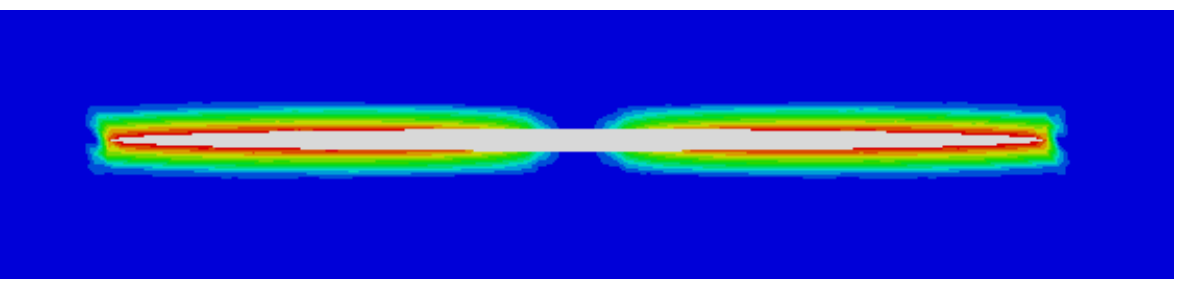

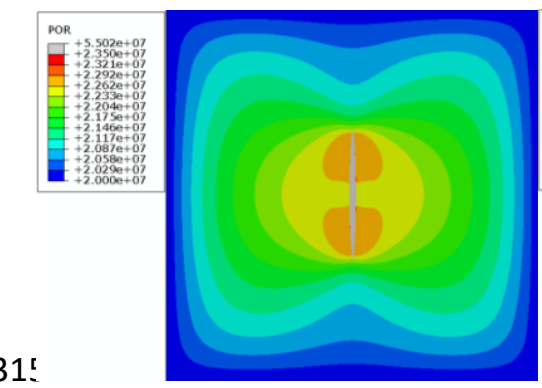

316

317

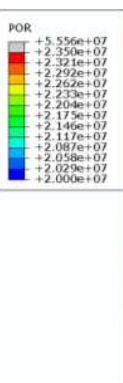

(a) Stress difference 5MPa

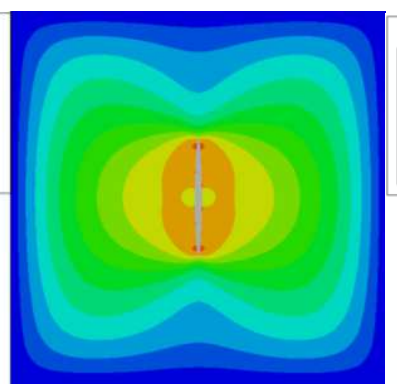

(b) Stress difference 8 MPa
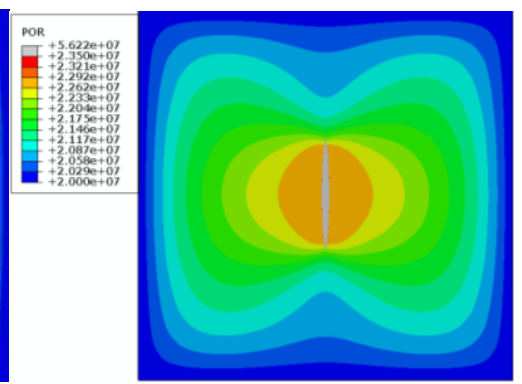

(c) Stress difference $10 \mathrm{MPa}$

Fig.9. Effect of stress difference on pore pressure 


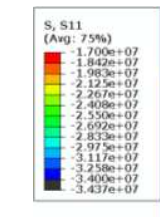

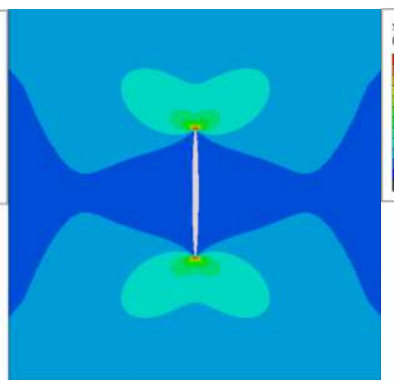

(a) Stress difference $5 \mathrm{MPa}$

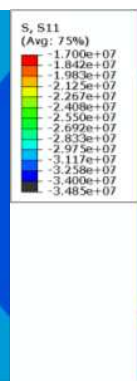

(b) Stress difference $8 \mathrm{MPa}$

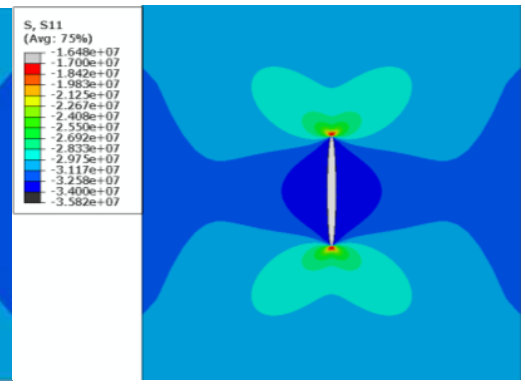

(c) Stress difference $10 \mathrm{MPa}$

Fig.10. Effect of stress difference on stress on $x$ direction

\subsection{Effect of friction angle on fracture propagation}

In order to study the influence of friction angle on hydraulic fracture propagation, the effects of friction angle on fracture width and length, injection pressure, fracture width at the wellbore, equivalent plastic strain, pore pressure and induced stress are simulated. It is assumed that the minimum horizontal principal stress is constant at $10 \mathrm{MPa}$, the horizontal principal stress difference is $5 \mathrm{MPa}$, and the injection time is $80 \mathrm{~s}$. The friction angle of the rock is $10^{\circ}, 20^{\circ}$ and $28^{\circ}$, respectively, and dilation angle is equal to friction angle. The calculation results are presented in figure 11-15.

Fig. 11 demonstrates that crack width decreases with the increasing friction angle, while crack length increases with the increasing friction angle. Lower friction angle cause the fracture tip to be blunter. When friction angle is $10^{\circ}$, plastic deformation at the injection point has obviously appeared in the early stage of crack expansion, leading to a significant increase of crack width near the wellbore. Figure 12 indicates that the crack width at the wellbore and injection pressure increases with friction angle decrease. When the friction angle decreases to $10^{\circ}$, fracture breakdown pressure and propagation pressure grow significantly, which leads to rapid increasing fracture width near the injection point. Figure 13 displays that the equivalent plastic strain area around the crack increases with the decreasing friction angle. Plastic strain occur obviously at the fracture entrance with friction angle of $10^{\circ}$, which is difficult for crack to extent. Figure 14-15 present that pore pressure and stress in $\mathrm{x}$ direction surround the fracture also increases with the decreasing friction angle.

Rock with low friction angle are easy to occur plastic deformation and form wide and short crack. 


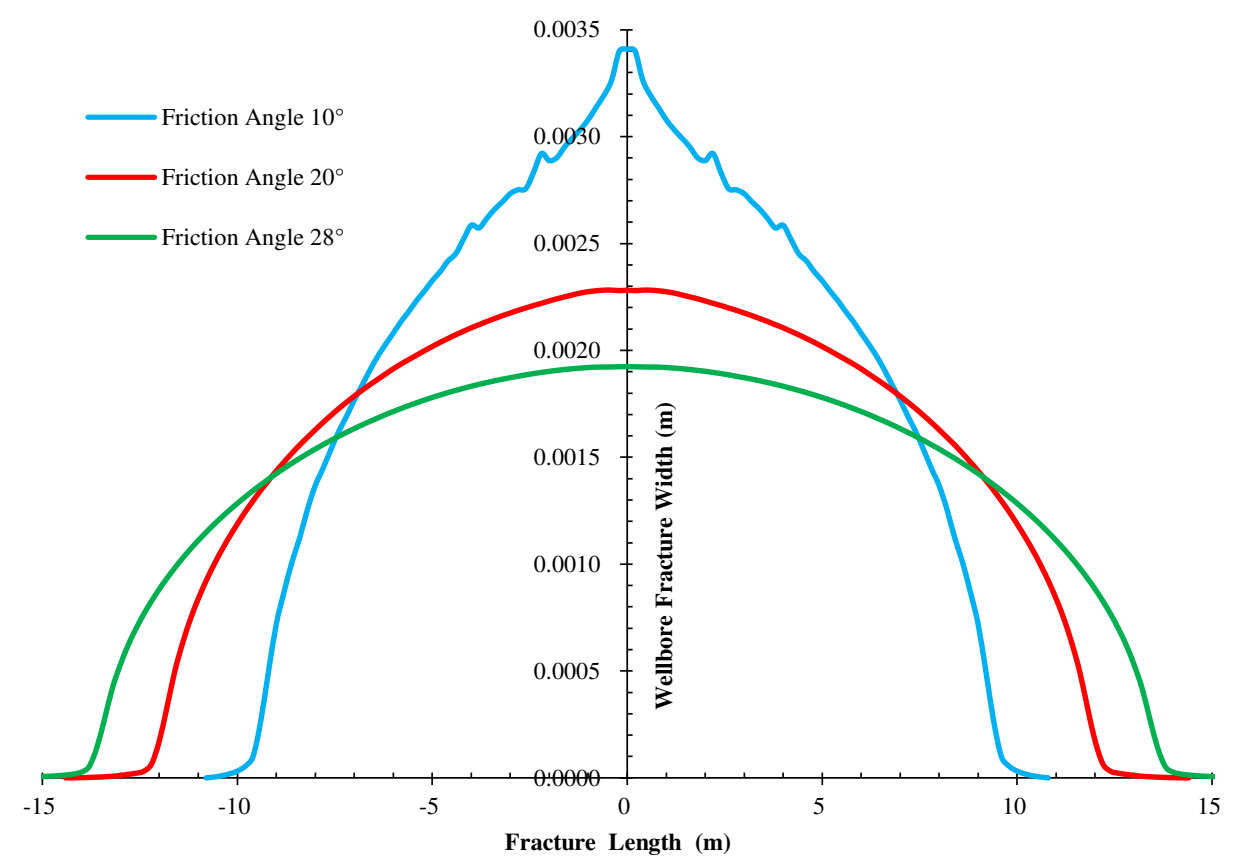

Fig.11. Effect of stress difference on fracture width and length
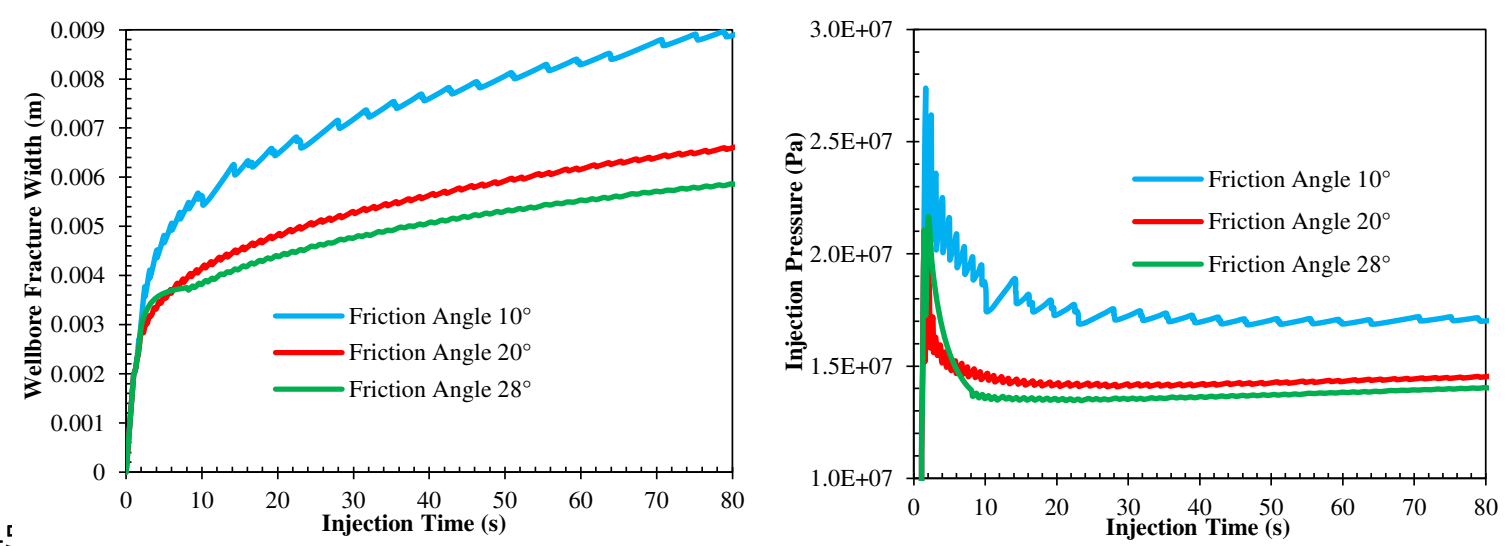

Fig.12. Effect of stress difference on wellbore fracture width and injection pressure
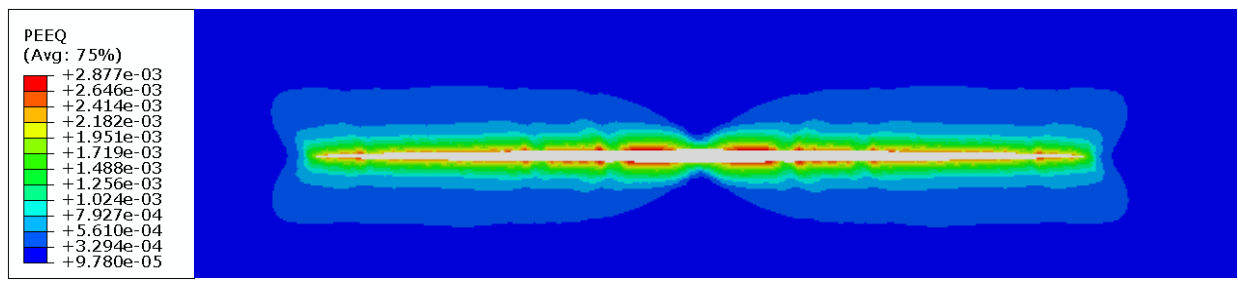

(a) Friction angle $10^{\circ}$

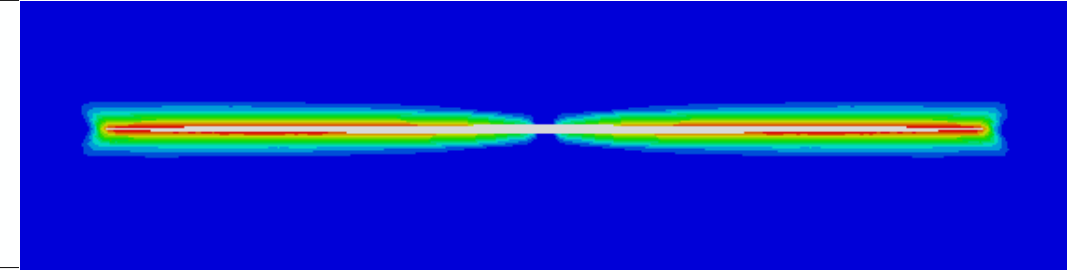




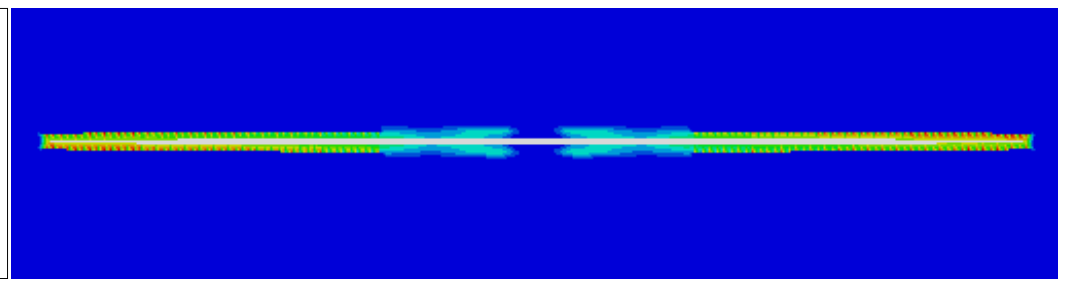

(c) Friction angle $28^{\circ}$

Fig.13. Effect of friction angle on equivalent plastic strain zone of fracture

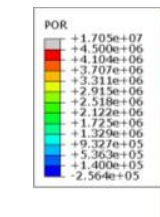

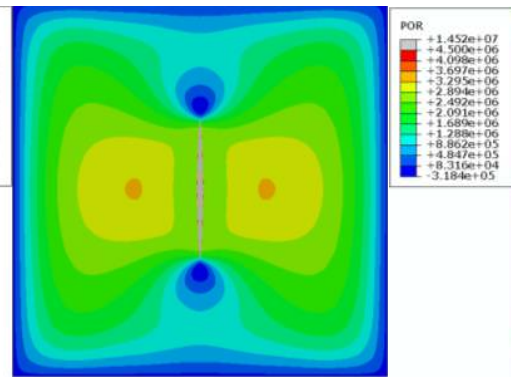

(a) Friction angle $10^{\circ}$

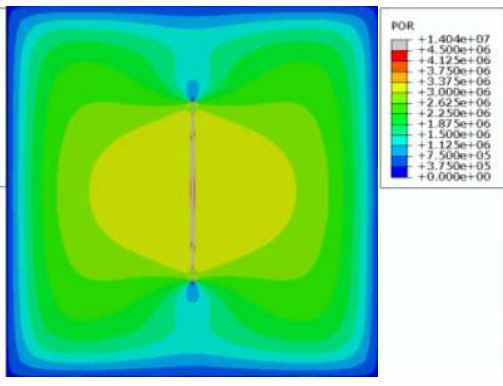

(b) Friction angle $20^{\circ}$

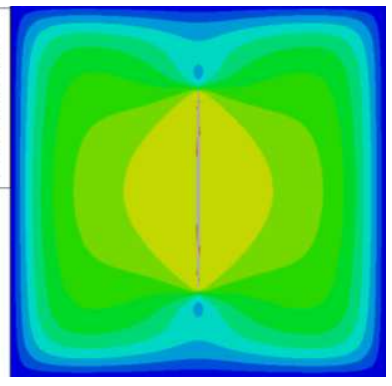

(c) Friction angle $28^{\circ}$

Fig.14. Effect of friction angle on pore pressure

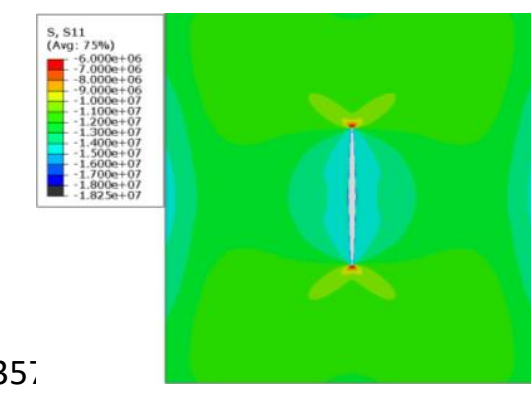

358 (a) Friction angle $10^{\circ}$
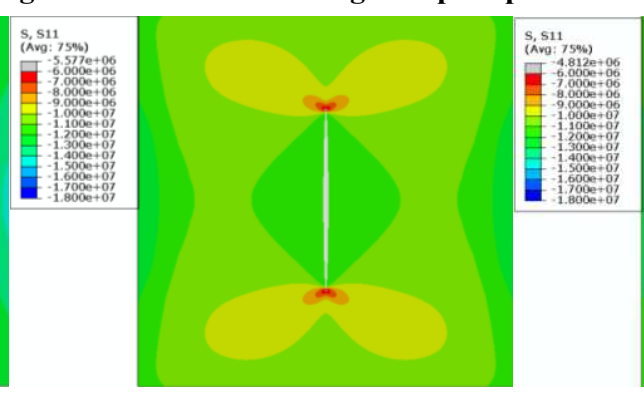

(b) Friction angle $20^{\circ}$

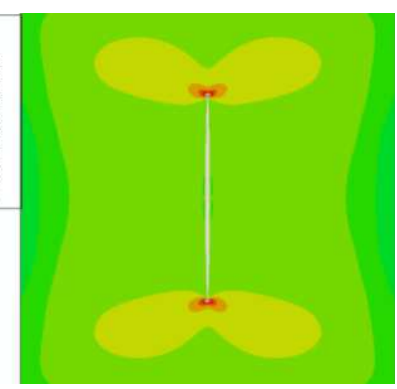

(c) Friction angle $28^{\circ}$

359

Fig.15. Effect of friction angle on stress on $\mathbf{x}$ direction

360

361

362

363

364

365

366

367

368

369

370

371

372

373

374

375

\subsection{Effect of dilation angle on fracture propagation}

The dilation angle reflects the change rate of rock volume, normal displacement and tangential displacement in the shearing process. To study the influence of dilation angle on hydraulic fracture propagation, the effects of dilation angle on fracture width and length, injection pressure, fracture width at the wellbore, equivalent plastic strain, pore pressure and induced stress are simulated. It is assumed that the dilation angle of the rock is $10^{\circ}, 20^{\circ}$ and $28^{\circ}$, respectively, and friction angle is $28^{\circ}$. The other input parameters are the same as section 4.2 . The calculation results are presented in figure 16-20.

Fig. 16 demonstrates that crack width decreases with the increasing dilation angle and this trend is not obvious. Figure 17 indicates that with injection time more than 20 s, dilation angle has little influence on injection pressure and fracture width at the wellbore. Figure 18 displays that the equivalent plastic strain around the crack increases with the decrease of dilation angle and the value of plastic strain is small. Figure 19-20 present that dilation angle has also little effect on pore pressure and stress on $\mathrm{x}$ direction. Compared with friction angle, dilation angle is less sensitive to fracture width and length, as well as injection pressure. 


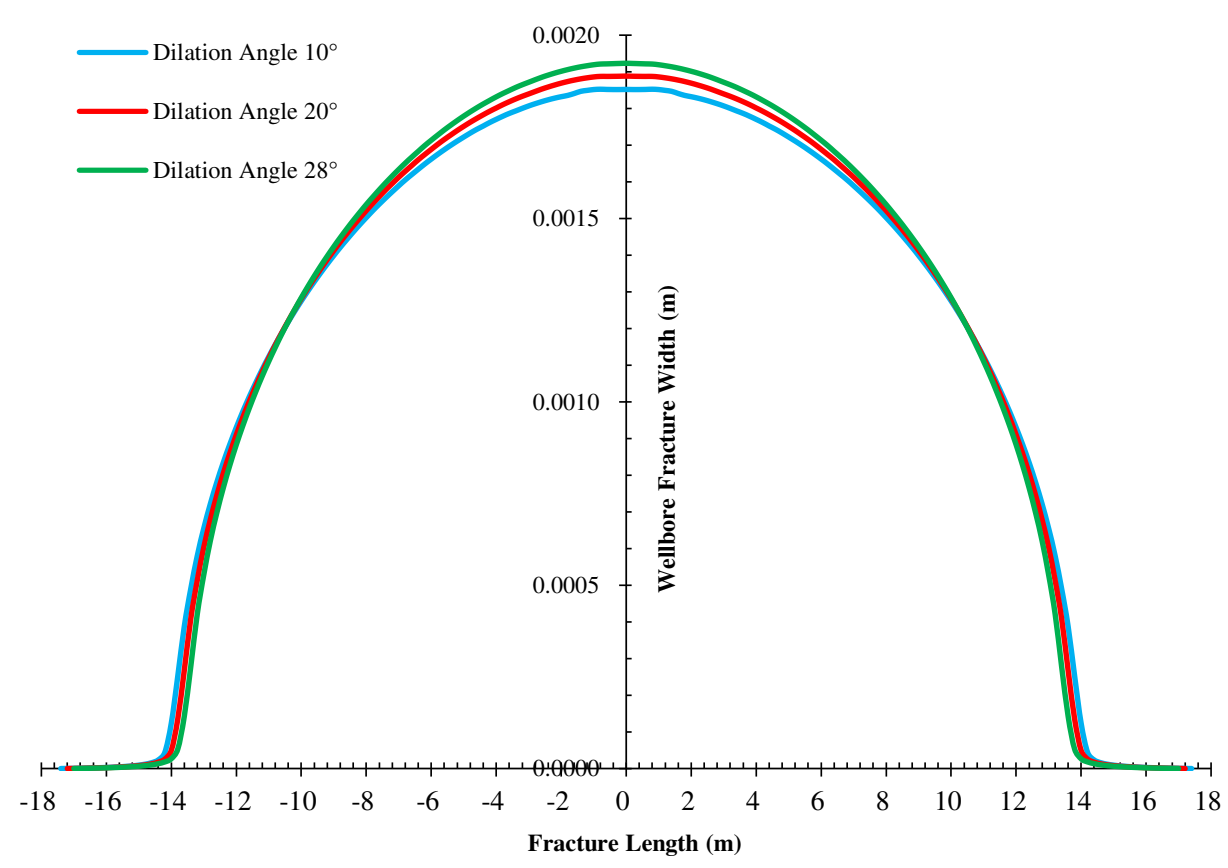

Fig.16. Effect of dilation angle on fracture width and length
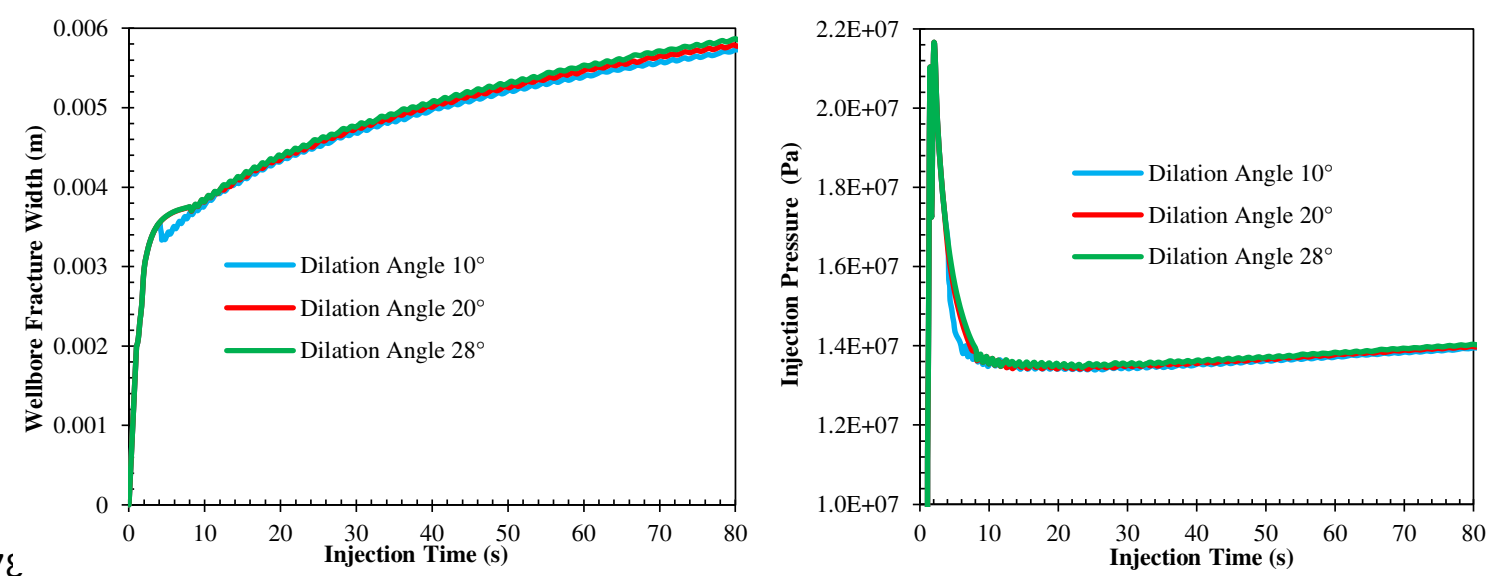

Fig.17. Effect of dilation angle on wellbore fracture width and injection pressure

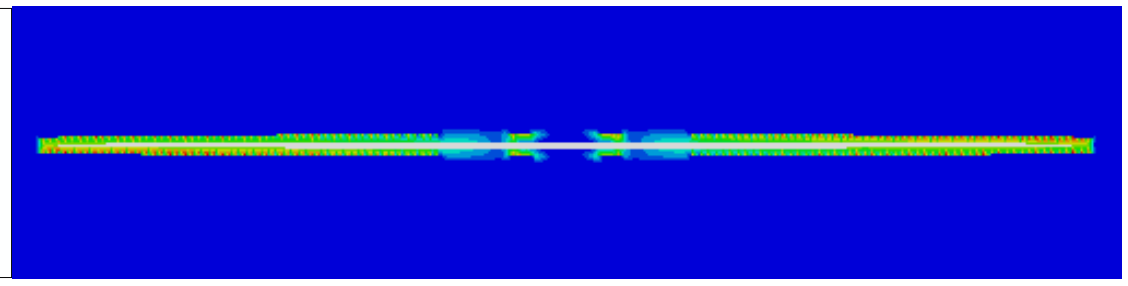

(a) Dilation Angle 10 ${ }^{\circ}$
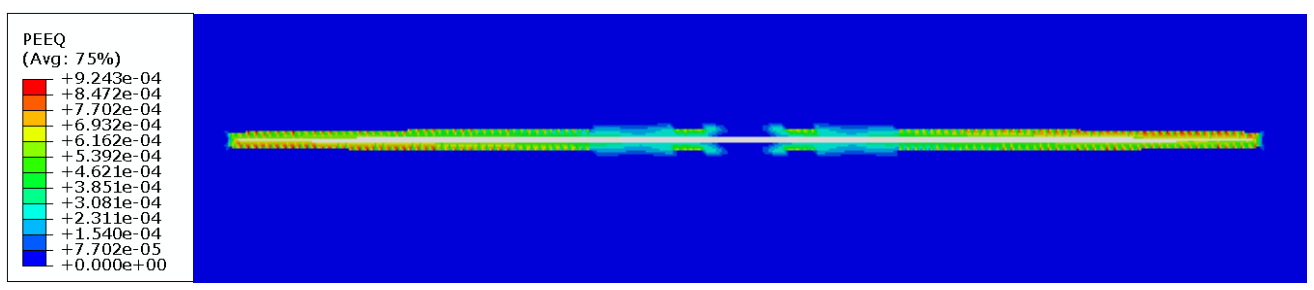


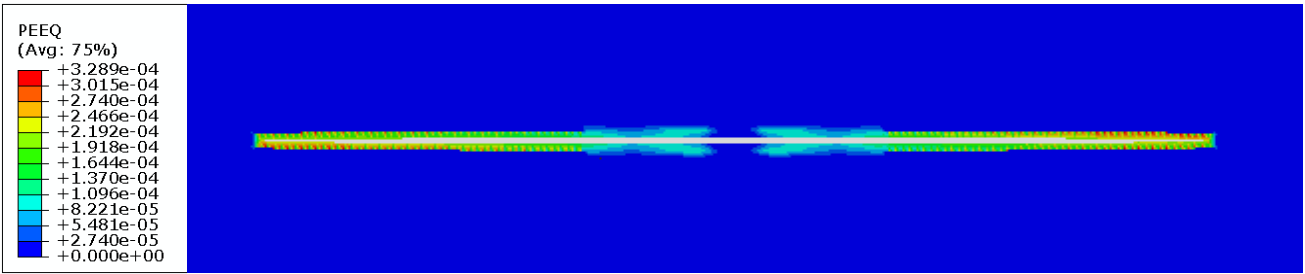

(c) Dilation Angle $28^{\circ}$

Fig.18. Effect of dilation angle on equivalent plastic strain zone of fracture

387

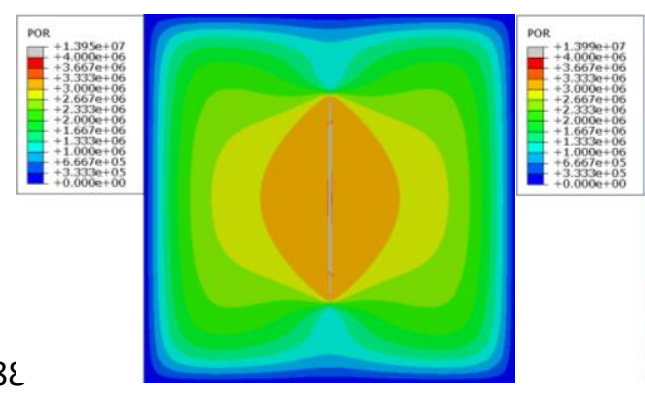

389

390

39: (a) Dilation angle $10^{\circ}$

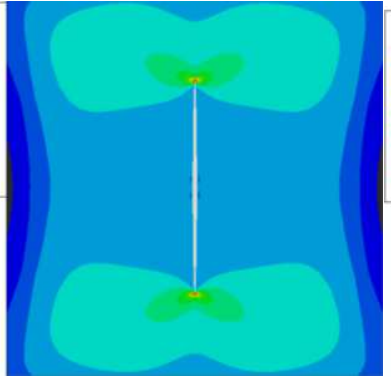

(a) Dilation angle $10^{\circ}$

\section{5、Conclusions} strain appears near the fracture tip. crack and blunt fracture tip.

\section{Acknowledgments}

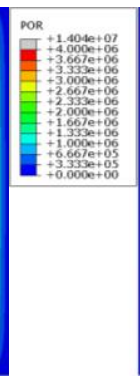

(b) Dilation angle $20^{\circ}$

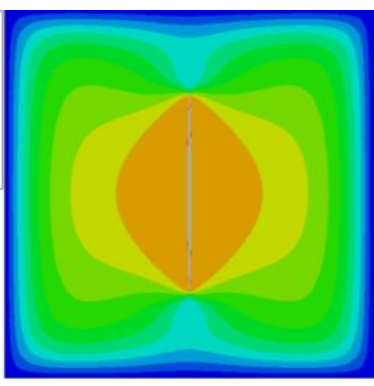

(c) Dilation angle $28^{\circ}$

Fig.19. Effect of dilation angle on pore pressure
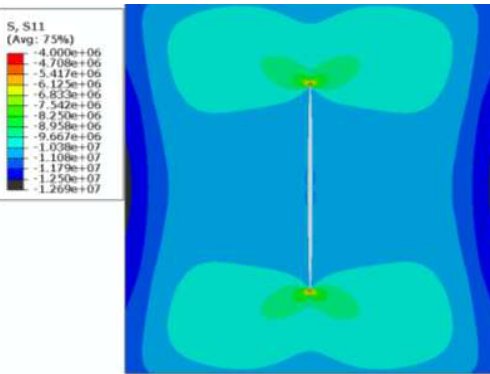

(b) Dilation angle $20^{\circ}$
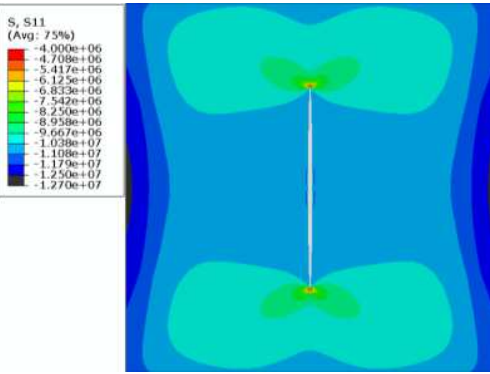

(c) Dilation angle $28^{\circ}$

Fig.20. Effect of dilation angle on stress on $x$ direction

A fluid-solid coupling elastoplasticity HF model is proposed. Calculation results of the model is compared with Papanastaiou's model and they have good agreements.

In comparison to elastic formation, elastic-plastic formation exhibit greater breakdown and propagation pressure, resulting wider and shorter fracture. Plastic deformation also lead to the fracture tip to be blunt. Plastic strain area grows with increasing injection time, and the largest plastic

Fracture width increases and fracture length decreases with the increasing stress difference. High stress difference or low friction angle are easy to occur large plastic deformation area, resulting great breakdown pressure, propagation pressure, induced stress in $\mathrm{x}$ direction and pore pressure. Soft formations with great stress difference or low friction angle is inclined to form wide and short

Compared with friction angle, dilation angle is less sensitive to plastic deformation and fracture parameters. For the formation with high stress difference and friction angle, the influence of plasticity effects on fracture propagation should not be ignored. 
This work was supported by the financial support of the National Natural Science Foundation of China (51404204) and National Major Science and Technology Projects of China: the Fu Ling shale gas development demonstration project (2016ZX05060).

\section{References}

Abu Al-Rub RK, Voyiadjis GZ., 2003. On the coupling of anisotropic damage and plasticity models for ductile materials. Int. J. Solids Struct. 40: 2611-2643.

Benzeggagh ML, Kenane M., 1996. Measurement of mixed-mode delamination fracture toughness of unidirectional glass/epoxy composites with mixed-mode bending apparatus. Compos Sci Technolgy. 56 (4): 439-449. https://doi.org/10.1016/0266-3538(96)00005-X.

Bohloli B, CJ de Pater., 2006. Experimental Study on Hydraulic Fracturing of Soft Rocks: Influence of Fluid Rheology and Confining Stress. J Pet Sci Eng, 53: 1-12.

Boone TJ, Ingraffea AR., 1990. A numerical procedure for simulation of hydraulically-driven fracture propagation in poroelastic media. International Journal for Numerical and Analytical Methods in Geomechanics 14 (1): 27-47. http://dx.doi.org/10.1002/nag.1610140103.

Busetti S, Mish K, Reches Z., 2012a. Damage and plastic deformation of reservoir rocks: Part 1. Damage fracturing. AAPG Bull. 96, 1687-1709.

Busetti S, Mish K, Hennings P, Reches Z., 2012b. Damage and plastic deformation of reservoir rocks: Part 2. Propagation of a hydraulic fracture. AAPG Bull. 96, 1711-1732.

Camacho GT, Ortiz M., 1996. Computational modelling of impact damage in brittle materials. Int. J. solids Struct. 33 (20): 2899-2938

Cheng, L., Luo, Z., Yu, Y., Zhao, L., Zhou, C., 2019. Study on the interaction mechanism between hydraulic fracture and natural karst cave with the extended finite element method, Engineering Fracture Mechanics, https://doi.org/10.1016/j.eng.

Chen Z, Bunger, AP, Zhang X. et al., 2009. Cohesive zone finite element-based modeling of hydraulic fractures. Acta Mechanica Solida Sinica 22 (5): 443-452. http://dx.doi.org/10.1016/S0894-9166(09) 60295-0.

Dahi-Taleghani A, Olson JE., 2011. Numerical modeling of multistranded-hydraulic-fracture propagation: accounting for the interaction between induced and natural fractures. SPE J. 16: 575-581.

De Pater, CJ, Dong Y, Bohloli B., 2007. Experimental Study of Hydraulic Fracturing in Sand as a Function of Stress and Fluid Rheology. In: Proceedings of the SPE Hydraulic Fracturing Technology Conference, College Station, Texas, USA. Society of Petroleum Engineers. https://doi.org/10.2118/105620-MS.

Dean RH, Schmidt JH., 2009. Hydraulic-Fracture Predictions With a Fully Coupled Geomechanical Reservoir Simulator. SPE J. 14 (4): 707-714. SPE-116470-PA. http://dx.doi.org/10.2118/116470-PA.

Elguedj T, Gravouil A, Combescure A., 2006. Appropriate extended functions for X-FEM simulation of plastic fracture mechanics. Comput. Methods Appl. Mech. Eng. 195: 501-515.

Geertsma J, De Klerk., 1969. A rapid method of predicting width and extent of hydraulic induced fractures. J. Pet.Technol. 246: 1571-1581.

Germanovich LN, Hurt RS, Ayoub JA, Siebrits E, Norman D, Ispas I, Montgomery CT., 2012. Experimental Study of Hydraulic Fracturing in Unconsolidated Materials. In: Proceedings of SPE International Symposium and Exhibition on Formation Damage Control, Lafayette, Louisiana, USA. Society of Petroleum Engineers. https://doi.org/10.2118/151827-MS.

Golovin E, Jasarevic H, Chudnovsky A, Dudley JW, Wong GK., 2010. Observation And Characterization of Hydraulic Fracture In Cohesionless Sand. In: Proceedings of the 44th U.S. Rock Mechanics Symposium and 
5th U.S.-Canada Rock Mechanics Symposium, Salt Lake City, Utah. American Rock Mechanics Association. ARMA-10-359.

$\mathrm{Hu}$ YQ, Zhao J, Zhao JZ, et al. Coiled tubing friction reduction of plug milling in long horizontal well with vibratory tool. J Pet Sci Eng., 2019, 177: 452-465. https://doi.org/10.1016/j.petrol.2019.02.042

Lin H, Deng JG, Liu W, Xie T, Xu J, Liu HL., 2018. Numerical simulation of hydraulic fracture propagation in weakly consolidated sandstone reservoirs. Journal of Central South University, 25(12): 2944-2952. https://doi.org/10.1007/s11771-018-3964-8.

Liu WZ, Yao J, Zeng QD., 2019. Numerical simulation of hydraulic fracture propagation in deep reservior (in Chinese). Sci Sin Tech, 49(2): 223-233, https://doi.org/10.1360/N092017-00207.

M. Brünig., 1999. Numerical simulation of the large elastic-plastic deformation behavior of hydrostatic stresssensitive solids. International Journal of Plasticity. 15(11):1237-1264.

Ma J, Zhao G, Khalili N., 2016. A fully coupled flow deformation model for elasto-plastic damage analysis in saturated fractured porous media. International Journal of Plasticity, 76, 29-50. https://doi.org/10.1016/j.ijplas.2015.07.011.

Nguyen VP, Lian H, Rabczuk T, Bordas S, 2017. Modelling hydraulic fractures in porous media using flow cohesive interface elements. Eng. Geol. 225, 68-82

Nordgren RP., 1972. Propagation of a Vertical Hydraulic Fracture. J Pet Technol. 12(4): 306-314. SPE-3009-PA. http://dx.doi.org/10.2118/3009-PA.

Omori Y, Jin S, Ito T, Nagano Y, Sekine K., 2013. Experimental Study of Hydraulic Fracturing in Unconsolidated Sands Using X-ray CT Method. In: Proceedings of the 47th U.S. Rock Mechanics/Geomechanics Symposium, San Francisco, California. American Rock Mechanics Association. ARMA-2013-660.

Perkins TK, Kern LR., 1961. Widths of Hydraulic Fractures. J Pet Technol. 13(9): 937-949. SPE-89-PA. http://dx.doi.org/10.2118/89-PA.

P Menetrey, KJ Willam., 1995. Triaxial failure criterion for concrete and its generalization. ACI Structural Journal. 99: 311-318.

Papanastasiou P.,1997. The influence of plasticity in hydraulic fracturing. International Journal of Fracture. 84(1):61-79. http://dx.doi.org/10.1023/A:1007336003057.

Papanastasiou P.,1999. An efficient algorithm for propagating fluid driven fractures. Computational Mechanics. 24:258-267.

Saouma V E, Ayari M L, Leavell D A., 1987. Mixed mode crack propagation in homogeneous anisotropic solids. Engineering Fracture Mechanics, 27(2): 171-184. https://doi.org/10.1016/0013-7944(87)90166-4.

Sarris E, Papanastasiou P., 2012. Modeling of Hydraulic Fracturing in a Poroelastic Cohesive Formation. Int. J. Geomech. 12 (2):160-167. http://dx.doi.org/10.1061/(ASCE)GM.1943-5622.0000121.

Shojaei A, Dahi Taleghani A, Li G., 2014. A continuum damage failure model for hydraulic fracturing of porous rocks. International Journal of Plasticity, 59, 199-212. https://doi.org/10.1016/j.ijplas.2014.03.003.

Sone H, Zoback MD., 2011. Visco-plastic Properties of Shale Gas Reservoir Rocks. Presented at the 45th U.S. Rock Mechanics/Geomechanics Symposium, San Francisco, California, USA, 26-29 June. ARMA-11-417

Sobhaniaragh B, Nguyen VP, Mansur WJ, Peters FC., 2018a. Pore pressure and stress coupling in closely-spaced hydraulic fracturing designs on adjacent horizontal wellbores. EUR J MECH A-SOLID. 67, 18-33. https://doi.org/10.1016/j.euromechsol.2017.08.010.

Sobhaniaragh B, Mansur WJ, Peters FC., 2018b. The role of stress interference in hydraulic fracturing of horizontal wells. INT J ROCK MECH MIN. 106:153-164. https://doi.org/10.1016/j.ijrmms.2018.04.024.

Tvergaard V, Hutchinson JW., 1992. The relation between crack growth resistance and fracture process parameters in elastic-plastic solids. J. Mech. Phys. Solids. 40(6): 1377-1397 
Van Dam DB, Papanastasiou P, De Pater CJ., 2002. Impact of rock plasticity on hydraulic fracture propagation and closure. SPE Production \& Facilities 17:149-159. SPE-78812-PA. http://dx.doi.org/10.2118/78812-PA Vermeer PA, Borst R., 1984. Non-Associated Plasticity for Soils, Concrete and Rock. HERON 29 (3): 3-64 Wang H., 2015. Numerical Modeling of Non-Planar Hydraulic Fracture Propagation in Brittle and Ductile Rocks using XFEM with Cohesive Zone Method. J Pet Sci Eng. http://dx.doi.org/10.1016/j.petrol.2015.08.010.

Wang H, Marongiu-Porcu M, Economides, MJ., 2016. Poroelastic and poroplastic modeling of hydraulic fracturing in brittle and ductile formations. SPE Prod Oper. 31: 47-59. https://doi.org/10.2118/168600-PA

Wu, K. 2014. Numerical Modeling of Complex Hydraulic Fracture Development in Unconventional Reservoirs. $\mathrm{PhD}$ degree dissertation, The University of Texas at Austin, Austin, Texas.

Yao Y., 2012. Linear Elastic and Cohesive Fracture Analysis to Model Hydraulic Fracture in Brittle and Ductile Rocks. Rock Mechanics and Rock Engineering. 45 (3): 375-387. http://dx.doi.org/10.1007/s00603-011-02110.

Zaki KS, Wang G, Meng F, Abou-Sayed AS., 2004. A 3-D Plastic Fracture Simulation To Assess Fracture Volumes In Compacting Reservoir. American Rock Mechanics Association. ARMA-04-648.

Zhao, J., Zhao, J.Z, Hu, Y.Q, et al. 2019. Numerical simulation of multistage fracturing optimization and application in coalbed methane horizontal wells, Engineering Fracture Mechanics, 224, 52-65.

Zhu HY, Zhao X, Guo J, Jin X, An F, Wang Y, Lai X., 2015. Coupled flow-stress-damage simulation of deviatedwellbore fracturing in hard-rock. J Nat Gas Sci Eng. 26: 711-724. https://doi.org/10.1016/j.jngse.2015.07.007

Zielonka, MG, et al., 2014. Development and validation of fully-coupled hydraulic fracturing simulation capabilities. In: Presented at the 2014 SIMULIA community conference, Providence RI. 
Figures

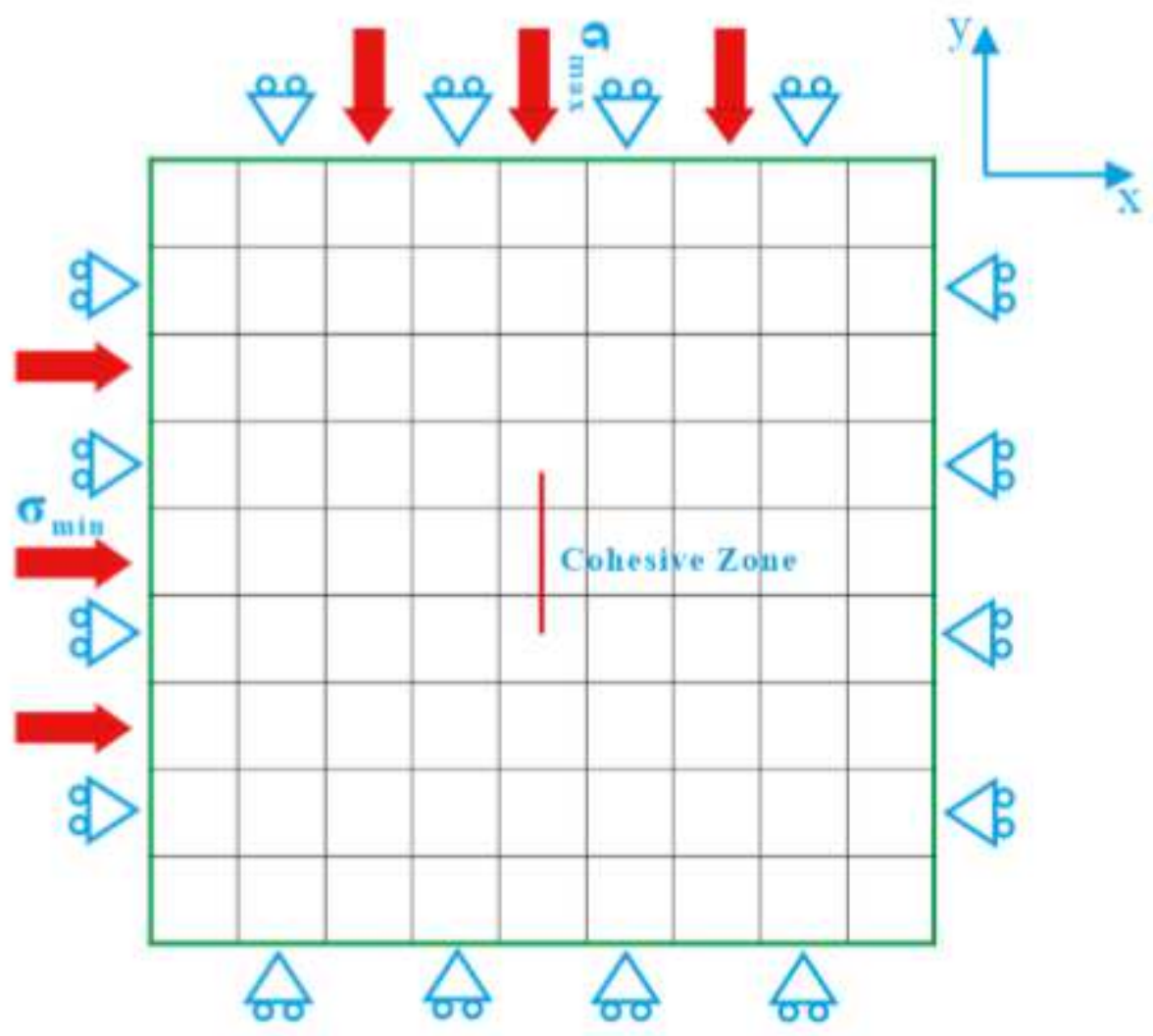

Figure 1

Geological model for hydraulic fracture simulation
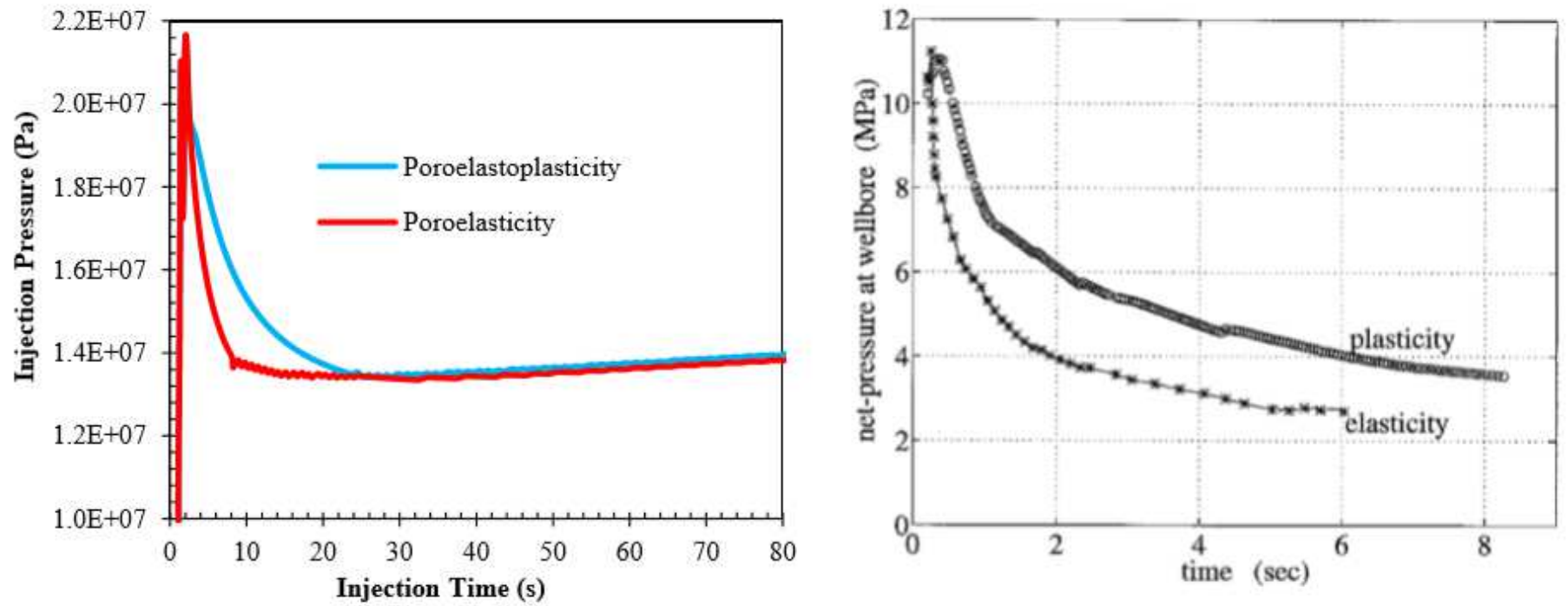

Figure 2

Comparison of injection pressure calculated by different models 


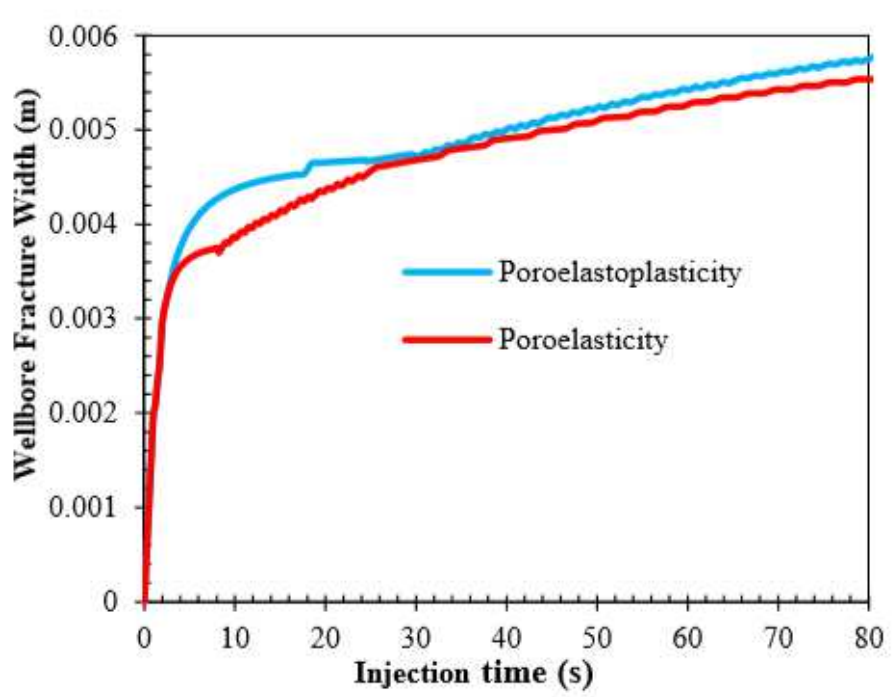

(a) Our model

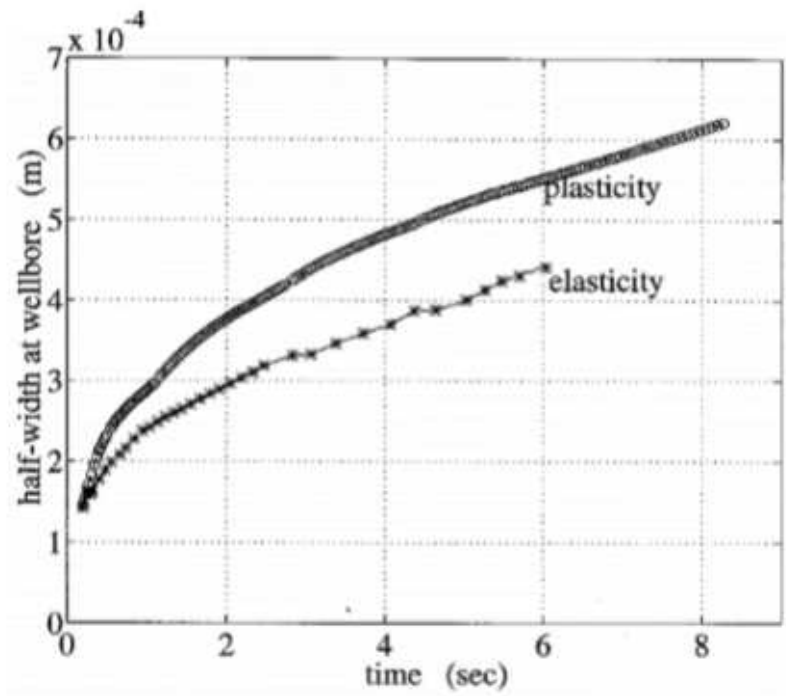

(b) Papanastaiou's model (Papanastasiou, 1997)

\section{Figure 3}

Comparison of wellbore fracture width with different time calculated by poroelastic and poroelastoplastic models

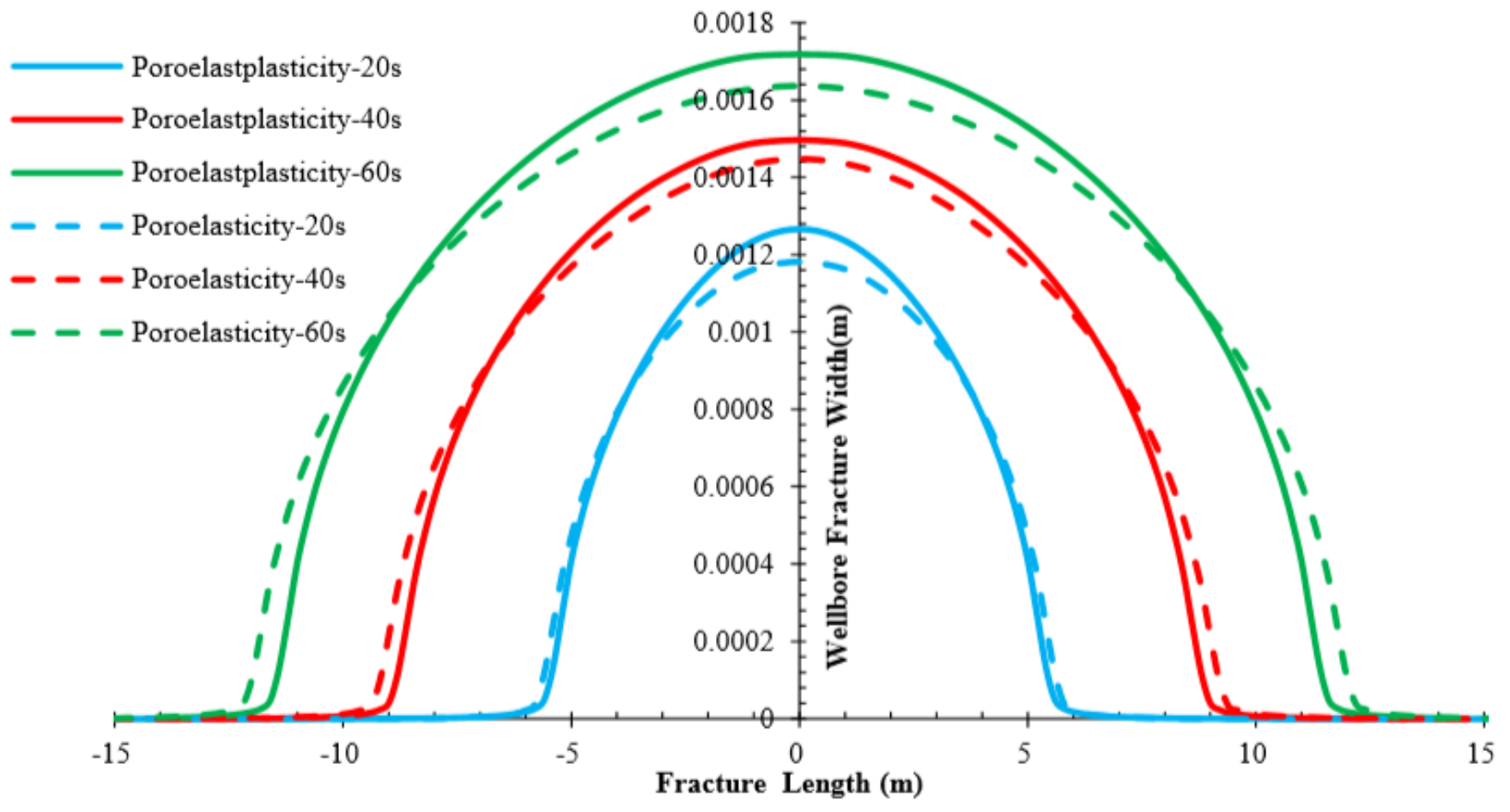

Figure 4

Comparison of fracture parameters with different time calculated by poroelastic and poroelastoplastic models 

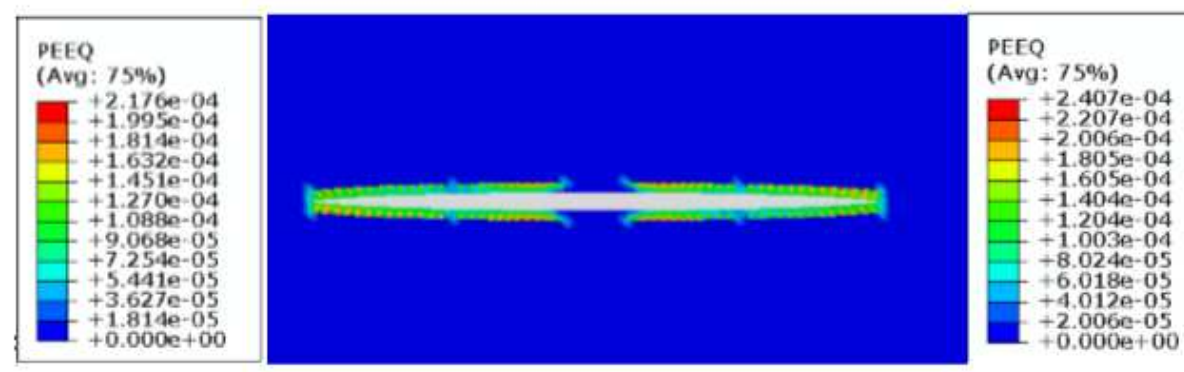

(a) Injection time at $20 \mathrm{~s}$
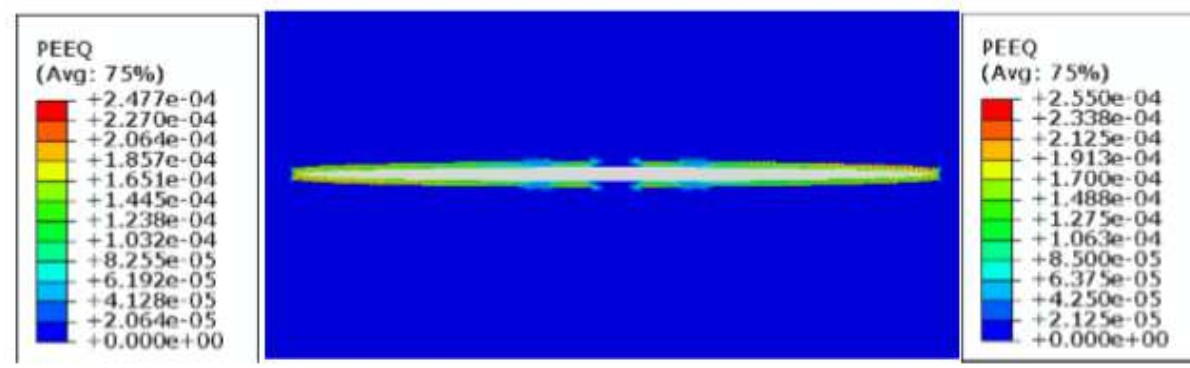

(c) Injection time at $60 \mathrm{~s}$

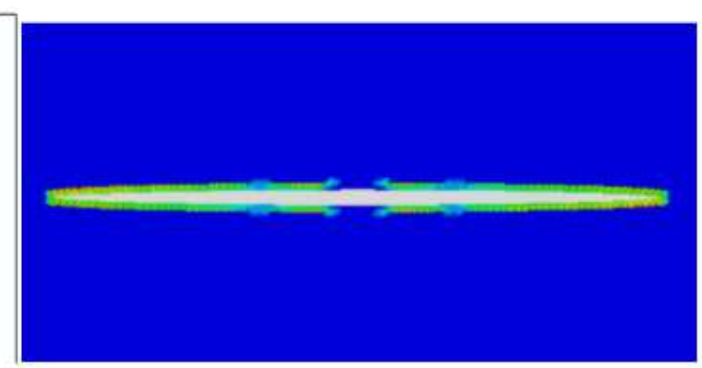

(b) Injection time at $40 \mathrm{~s}$

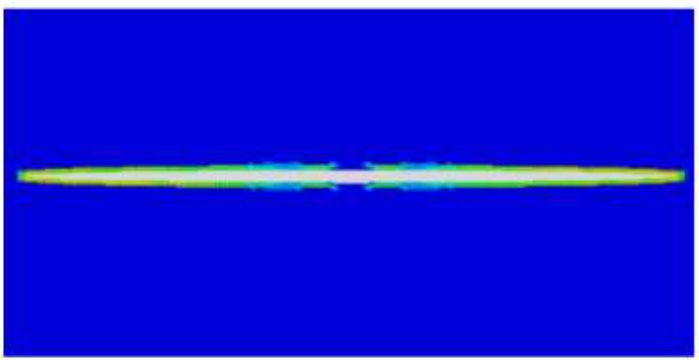

(d) Injection time at $80 \mathrm{~s}$

\section{Figure 5}

Equivalent plastic strain zone of fracture varies with injection time

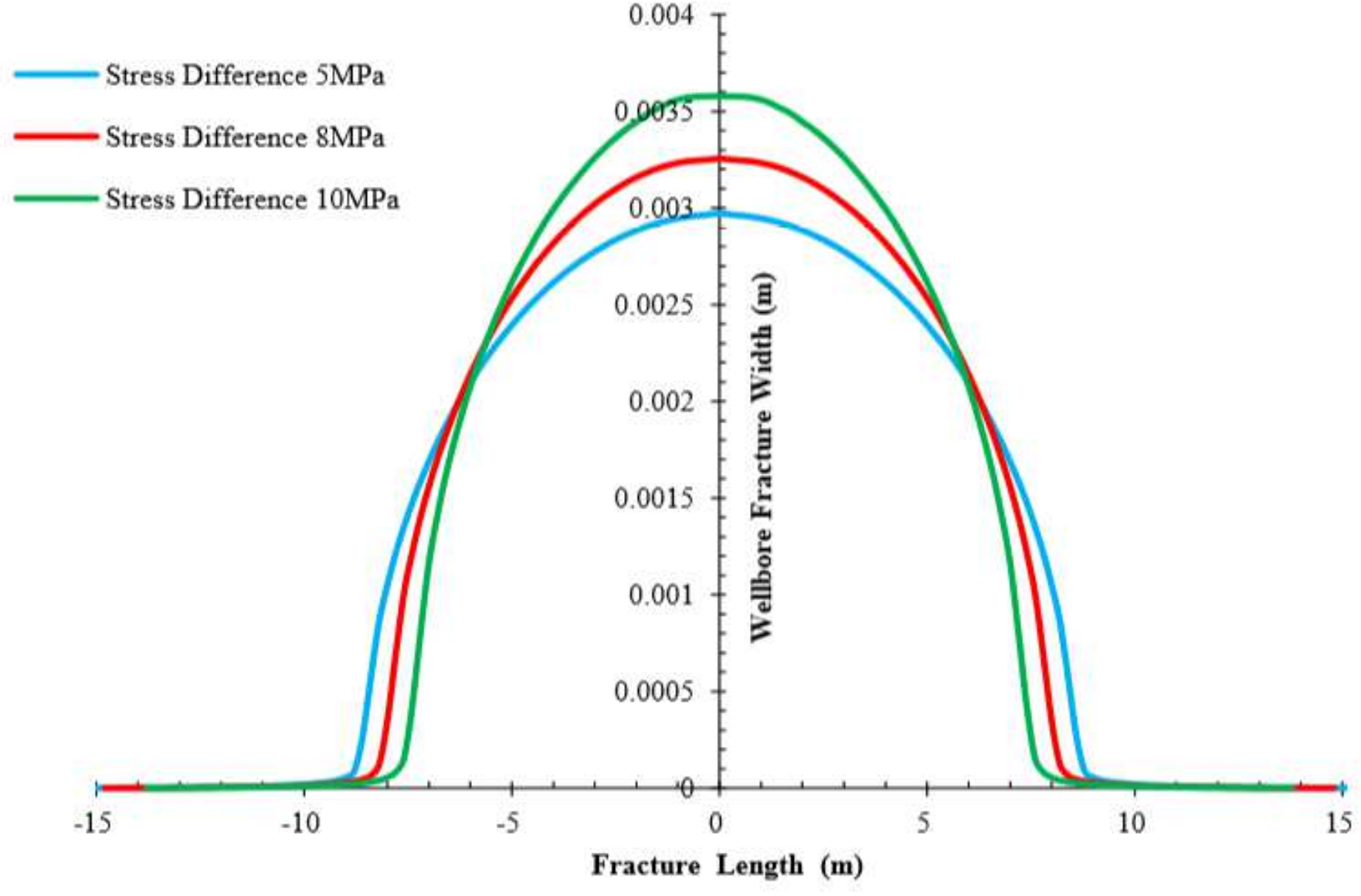

Figure 6 
Effect of stress difference on fracture width and length
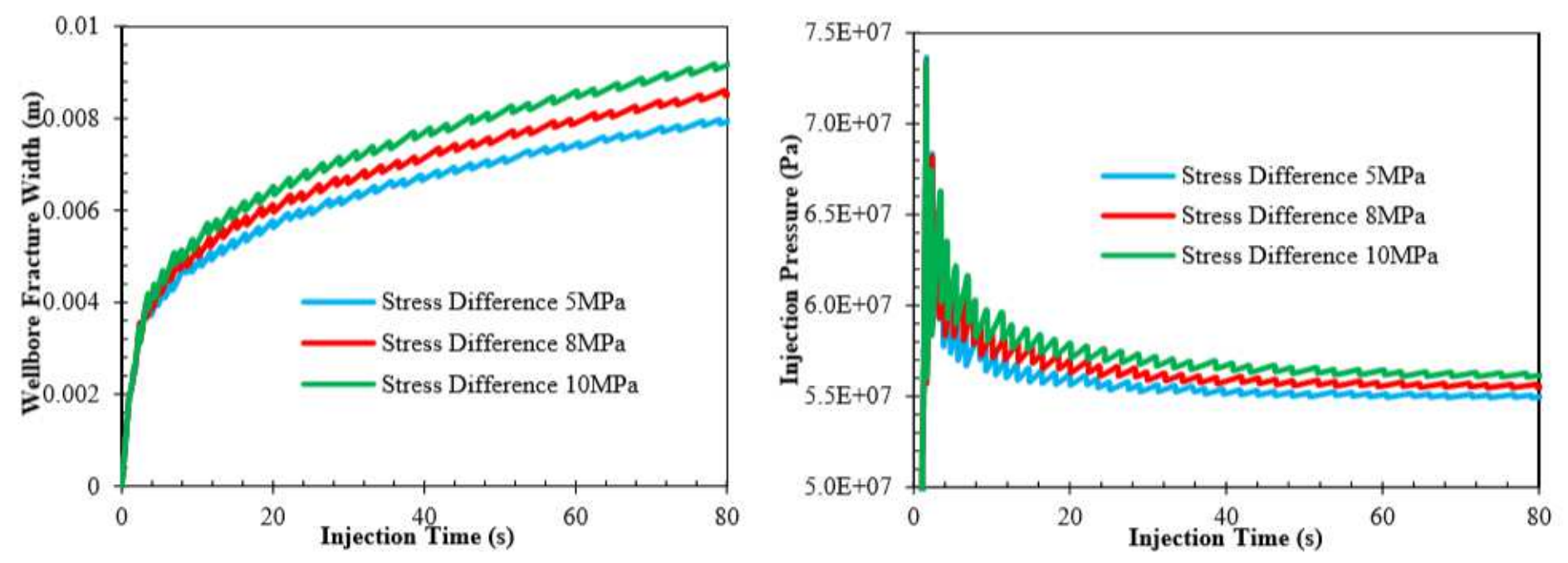

\section{Figure 7}

Effect of stress difference on wellbore fracture width and injection pressure 


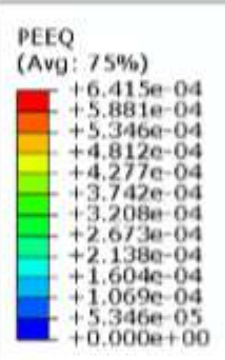

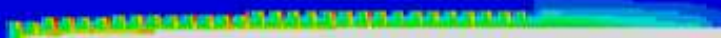

(1)

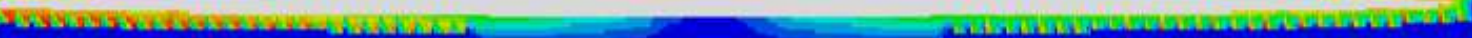

(a) Stress difference 5MPa

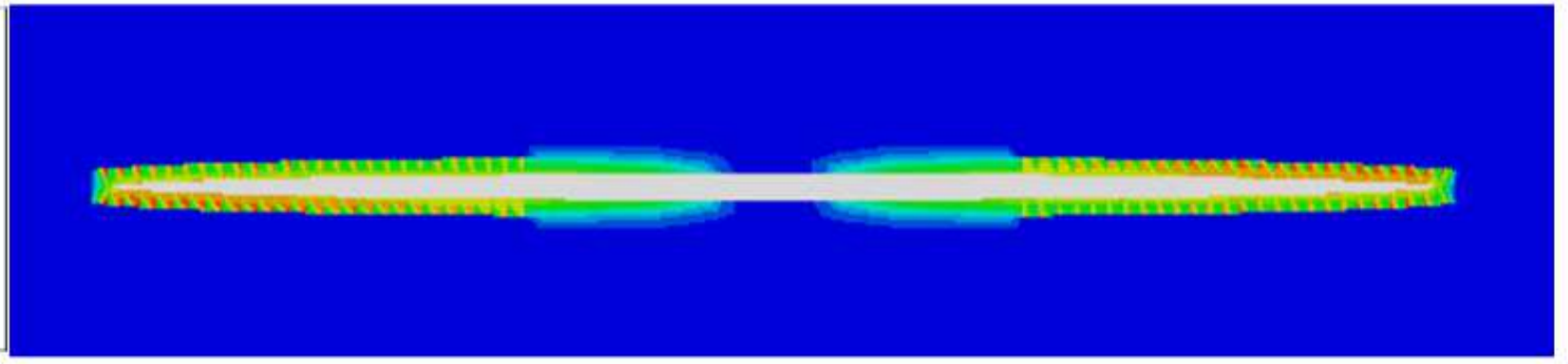

(b) Stress difference 8MPa

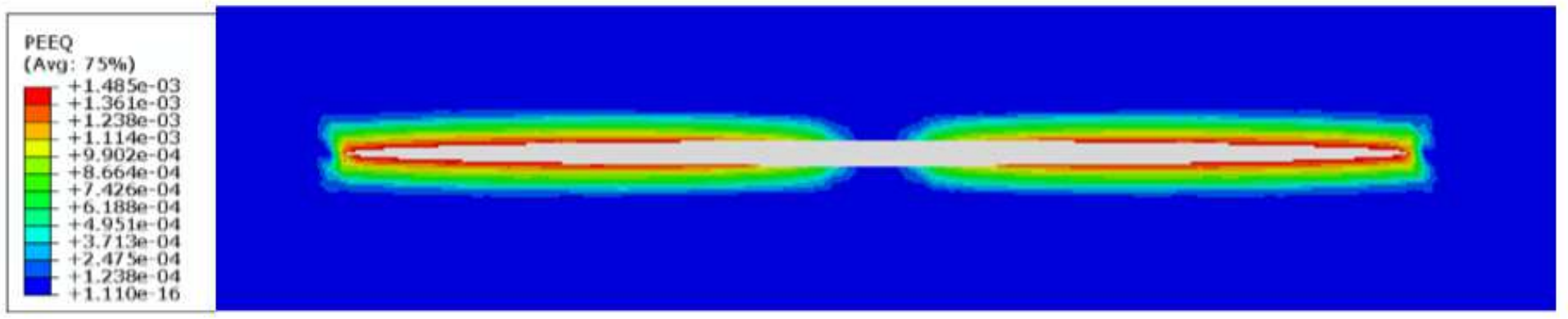

(c) Stress difference 10MPa

Figure 8

Effect of stress difference on equivalent plastic strain zone of fracture

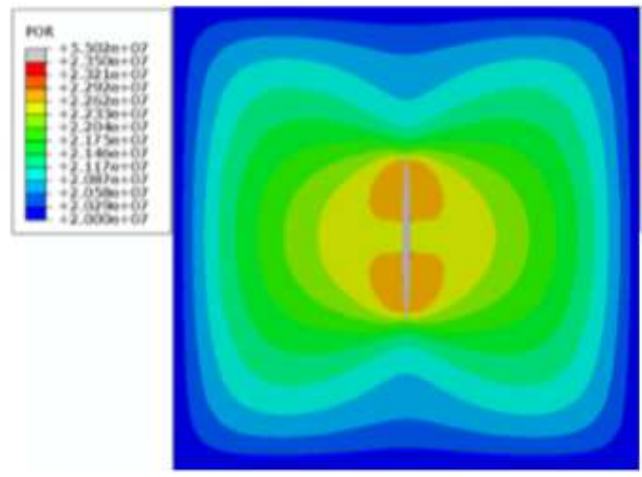

(a) Stress difference 5MPa

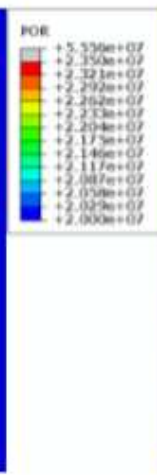

(b) Stress difference $8 \mathrm{MPa}$
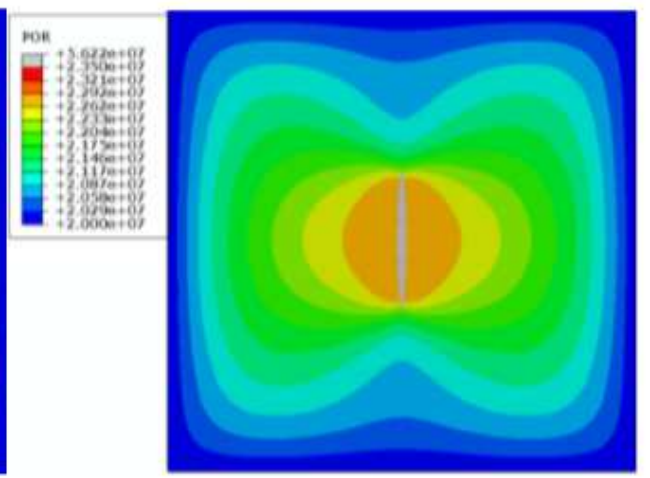

(c) Stress difference $10 \mathrm{MPa}$

Figure 9 
Effect of stress difference on pore pressure

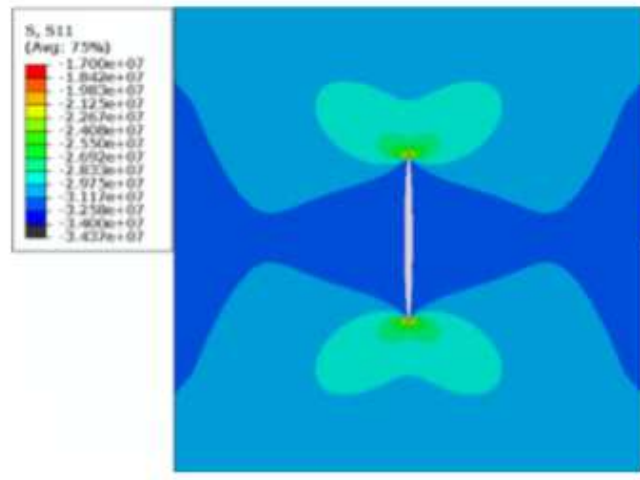

(a) Stress difference 5MPa

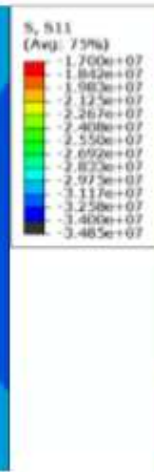

(b) Stress difference 8 MPa

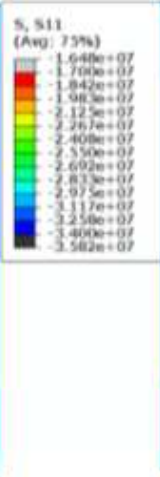

(c) Stress difference $10 \mathrm{MPa}$

Figure 10

Effect of stress difference on stress on $x$ direction

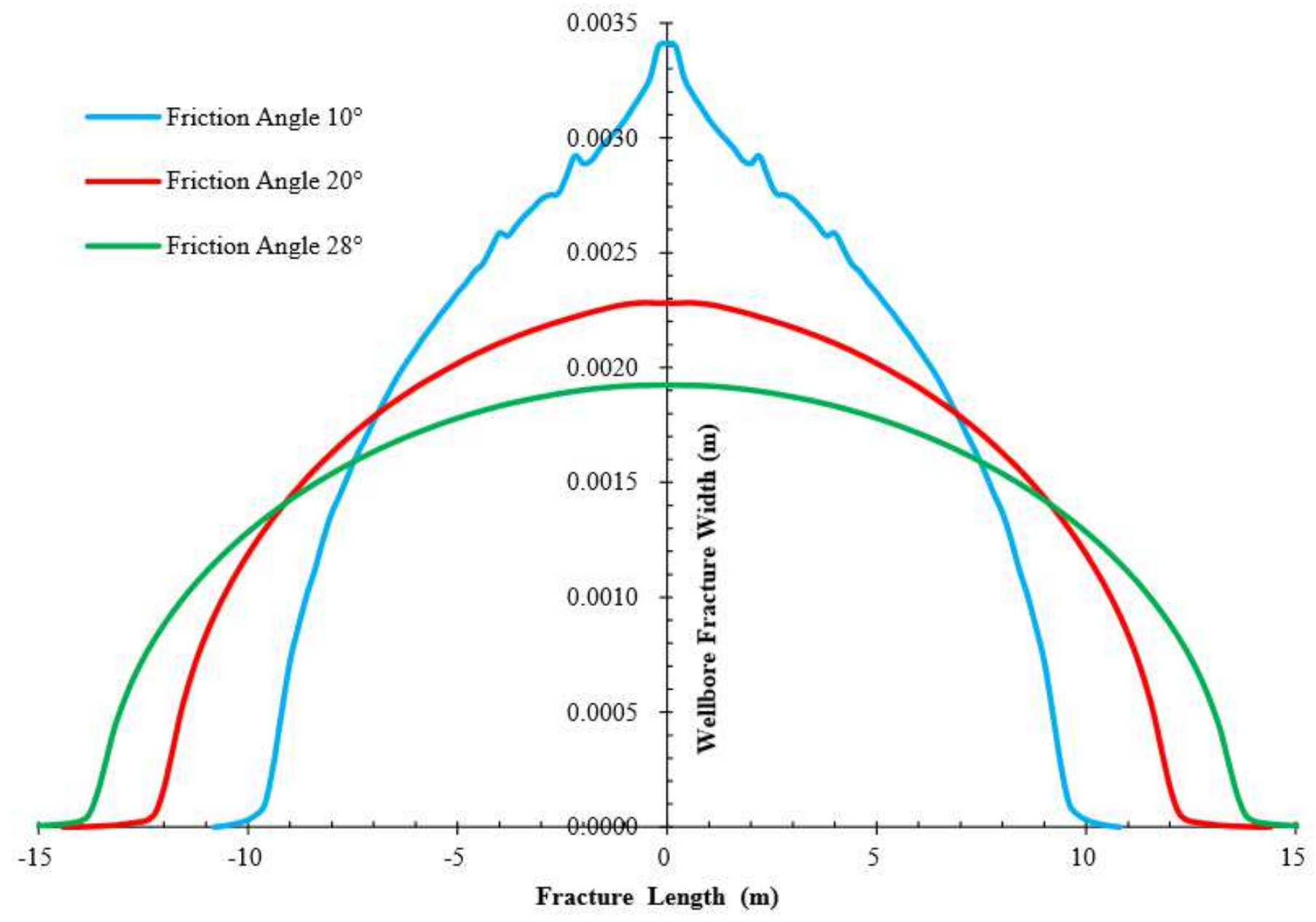

Figure 11

Effect of stress difference on fracture width and length 

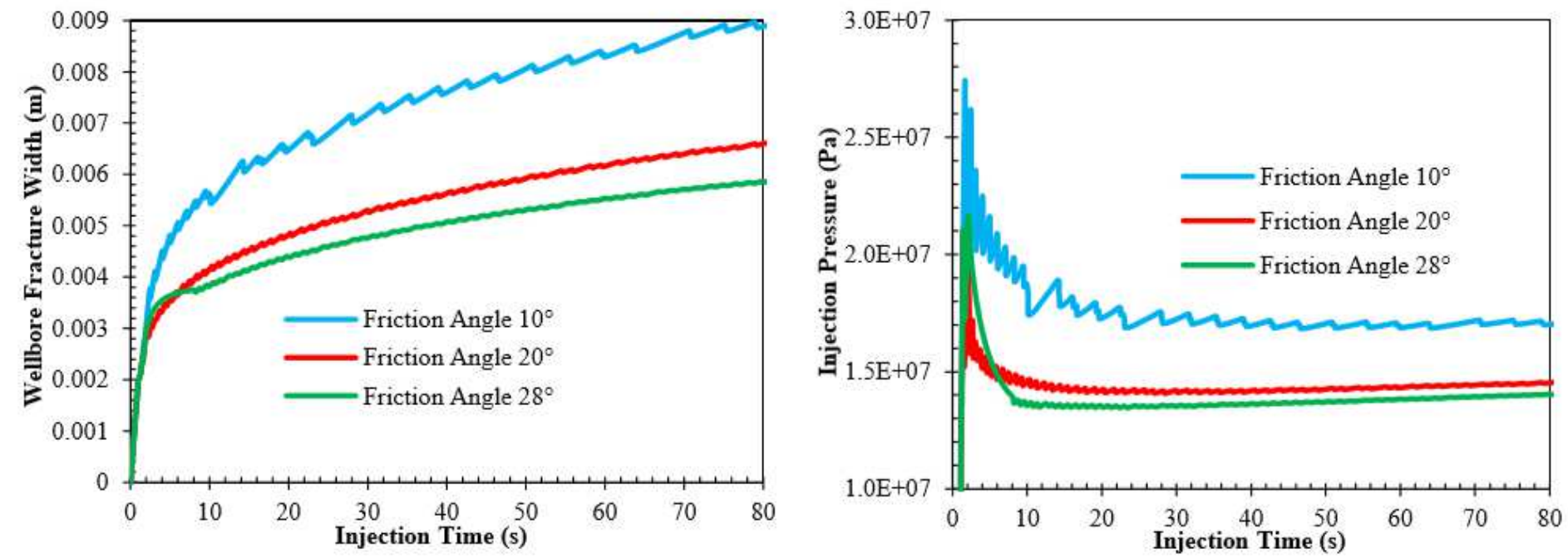

Figure 12

Effect of stress difference on wellbore fracture width and injection pressure 


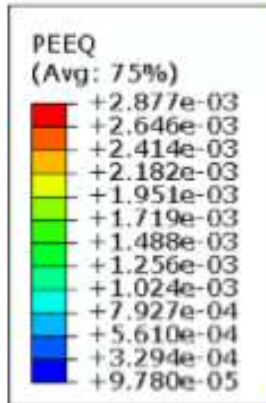

(a) Friction angle $10^{\circ}$

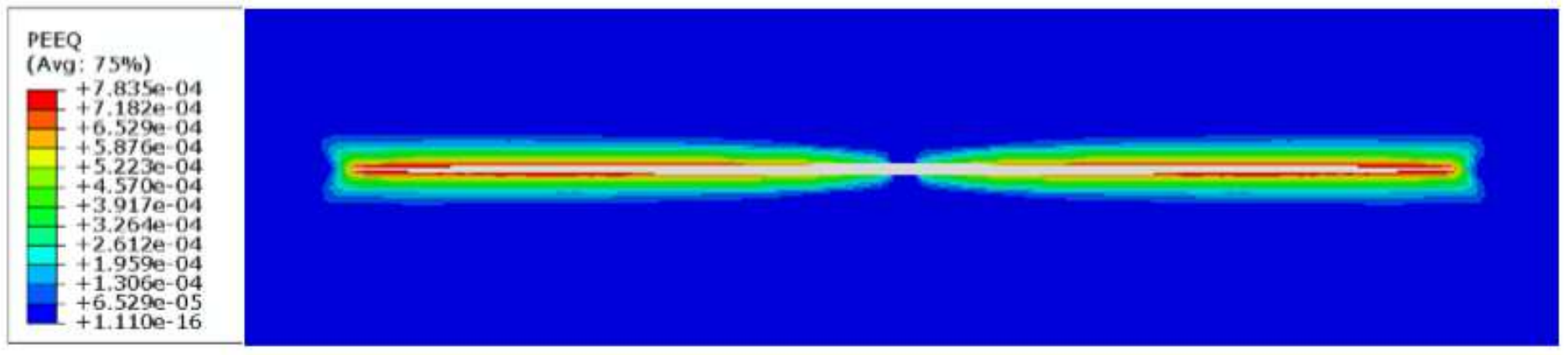

(b) Friction angle $20^{\circ}$
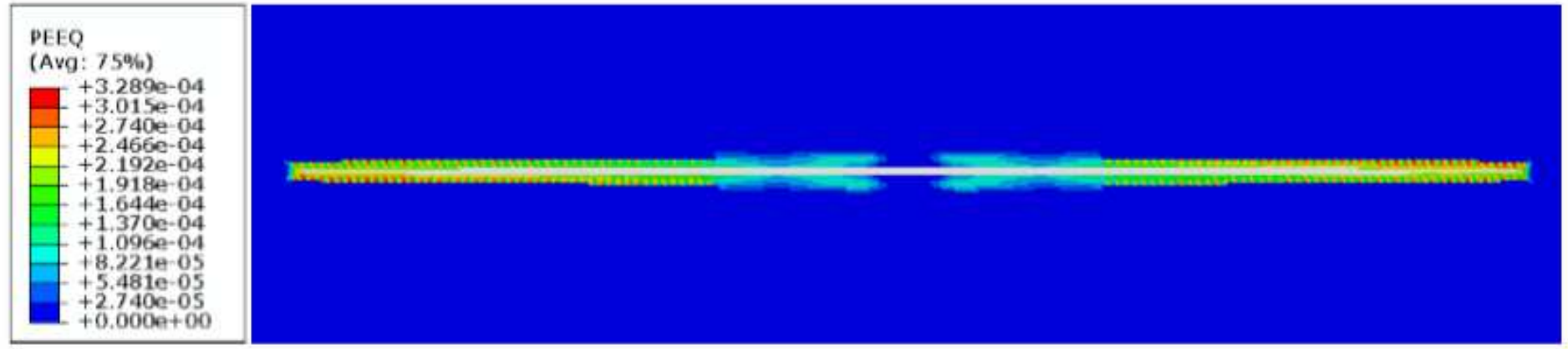

(c) Friction angle $28^{\circ}$

Figure 13

Effect of friction angle on equivalent plastic strain zone of fracture 


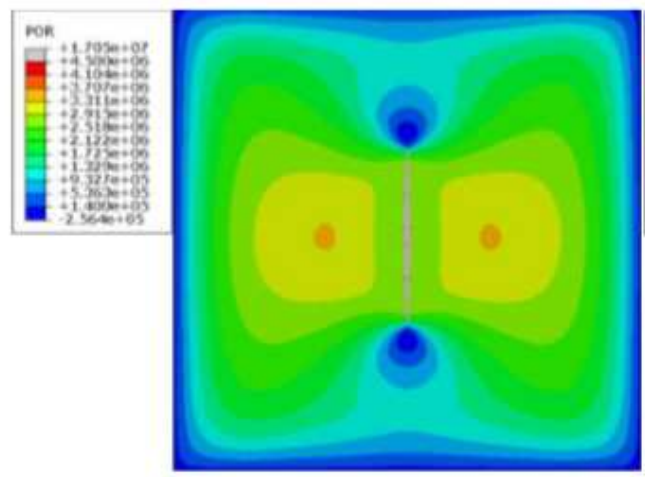

(a) Friction angle $10^{\circ}$

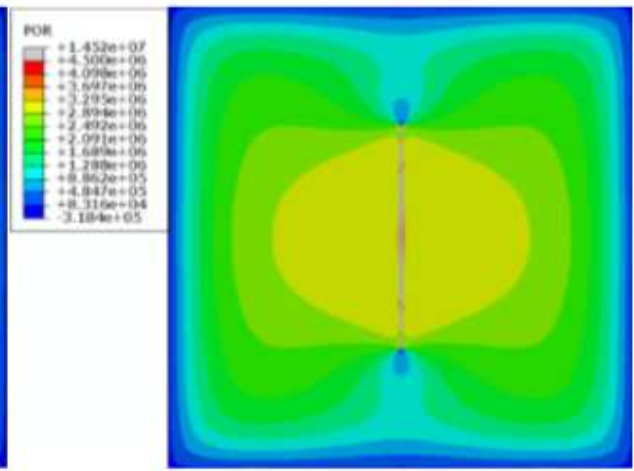

(b) Friction angle $20^{\circ}$

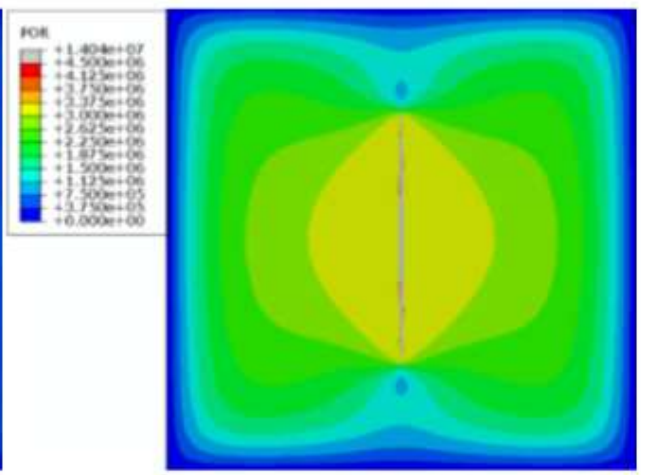

(c) Friction angle $28^{\circ}$

Figure 14

Effect of friction angle on pore pressure

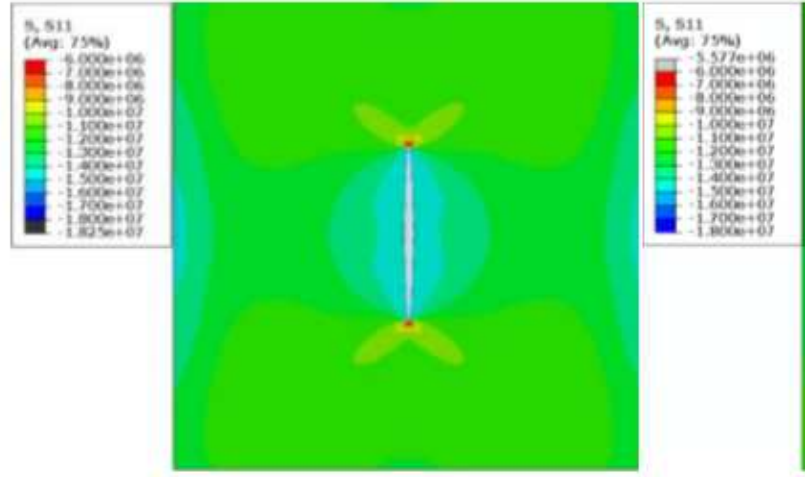

(a) Friction angle $10^{\circ}$

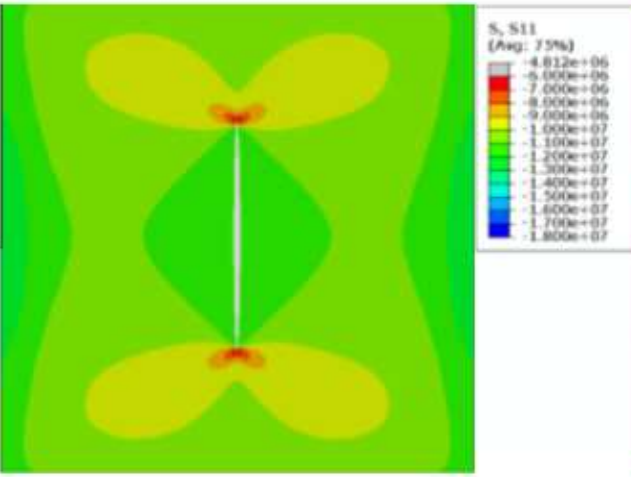

(b) Friction angle $20^{\circ}$

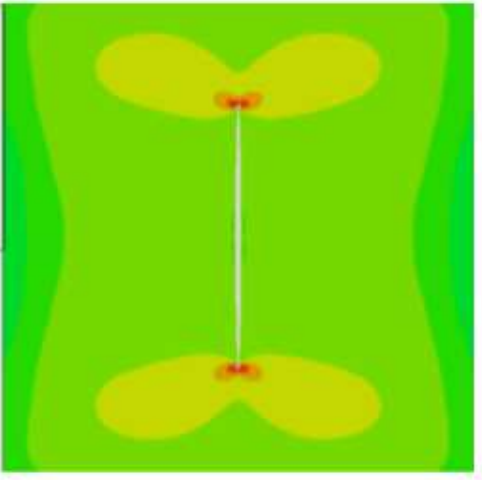

(c) Friction angle $28^{\circ}$

Figure 15

Effect of friction angle on stress on $\mathrm{x}$ direction 


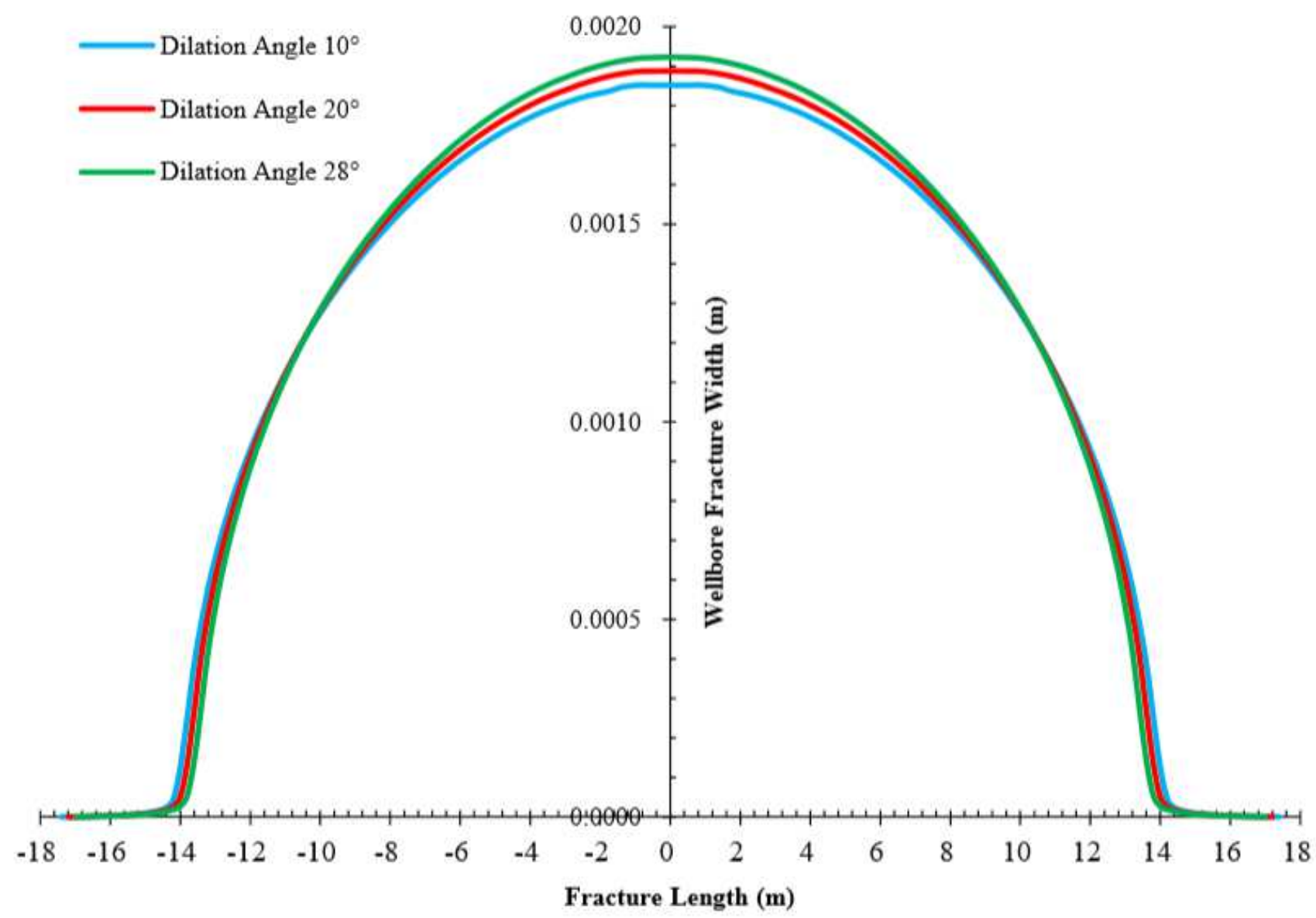

Figure 16

Effect of dilation angle on fracture width and length
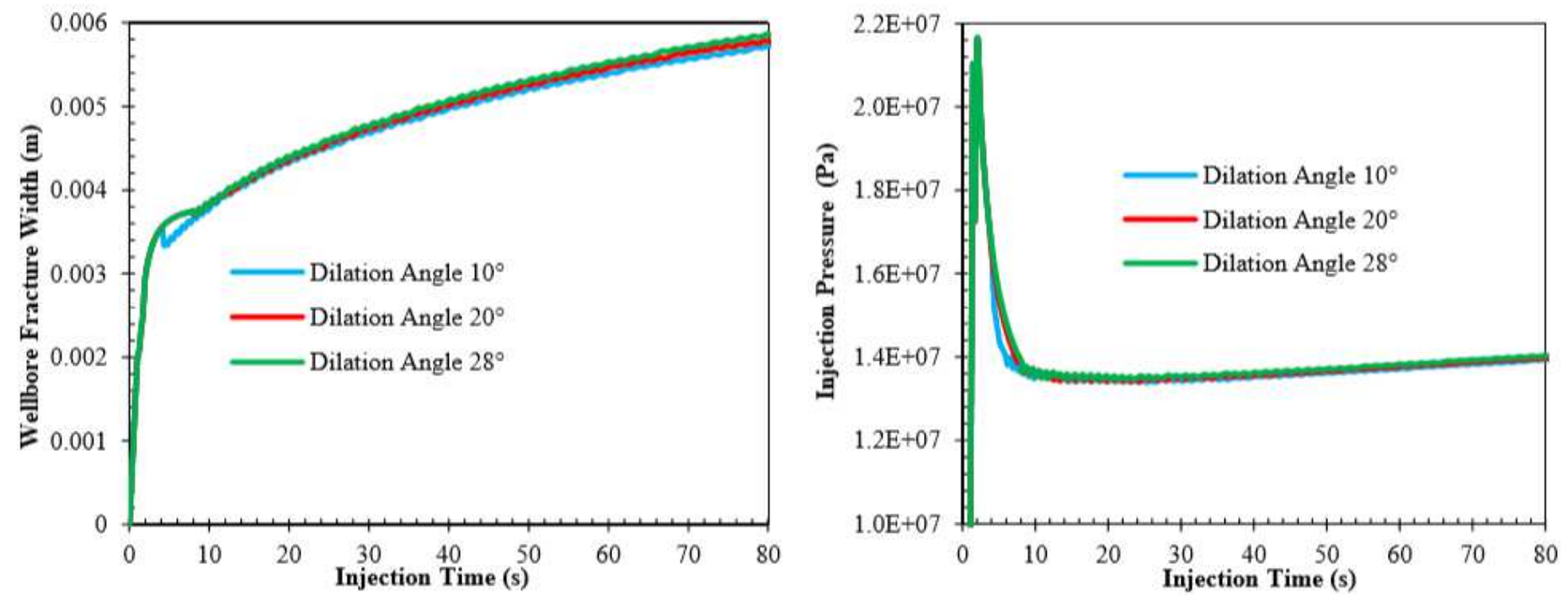

Figure 17

Effect of dilation angle on wellbore fracture width and injection pressure 


\section{PEEQ \\ (Avg: 75\%) \\ $+1.551 \mathrm{e}-03$ $+1.4220-03$ $+1.2934-03$ $+1.163 e-03$ $+1.034 \mathrm{e}-03$ +9.0480-04 $+7.755 e-04$ $+5.170 \mathrm{e}-04$ $+3.878 \mathrm{e}-04$ $+2.5850-04$

(a) Dilation Angle $10^{\circ}$

\begin{tabular}{|l} 
PEEQ \\
(Avg: $75 \%)$ \\
$+9.243 \mathrm{e} \cdot 04$ \\
$+8.472 \mathrm{e} \cdot 04$ \\
$+7.702 \mathrm{e} \cdot 04$ \\
$+6.932 \mathrm{e}-04$ \\
$+6.162 \mathrm{e}-04$ \\
$+5.392 \mathrm{e} \cdot 04$ \\
$+4.621 \mathrm{e} \cdot 04$ \\
$+3.851 \mathrm{e} \cdot 04$ \\
$+3.081 \mathrm{e}-04$ \\
$+2.311 \mathrm{e} \cdot 04$ \\
$+1.540 \mathrm{e}-04$ \\
$+7.702 \mathrm{e} \cdot 05$ \\
$+0.000 \mathrm{e}+00$ \\
\hline \\
\hline
\end{tabular}

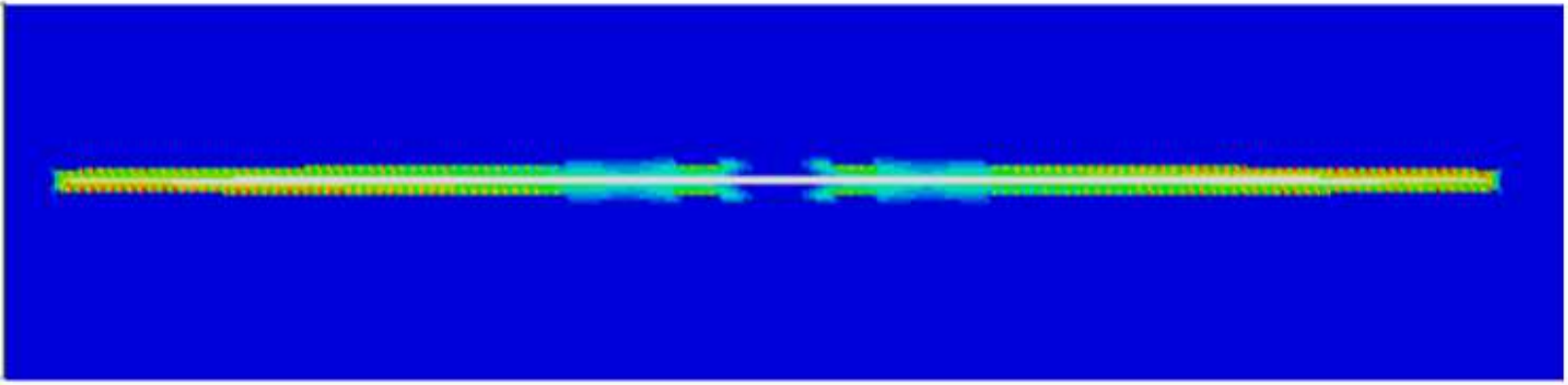

(b) Dilation Angle 20 ${ }^{\circ}$

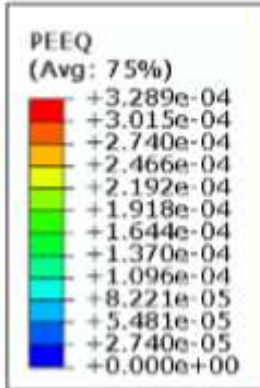

(c) Dilation Angle $28^{\circ}$

Figure 18

Effect of dilation angle on equivalent plastic strain zone of fracture 


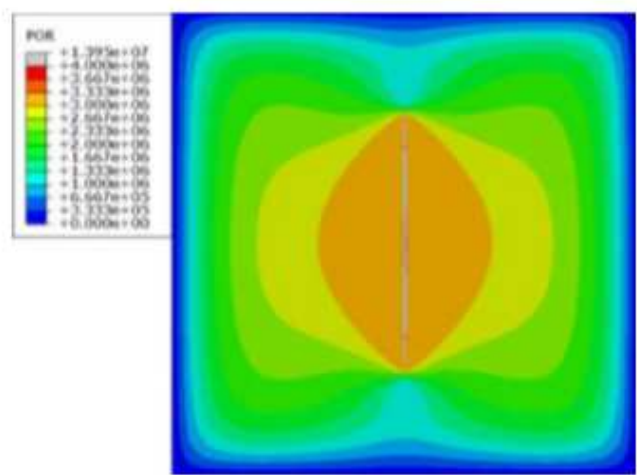

(a) Dilation angle $10^{\circ}$

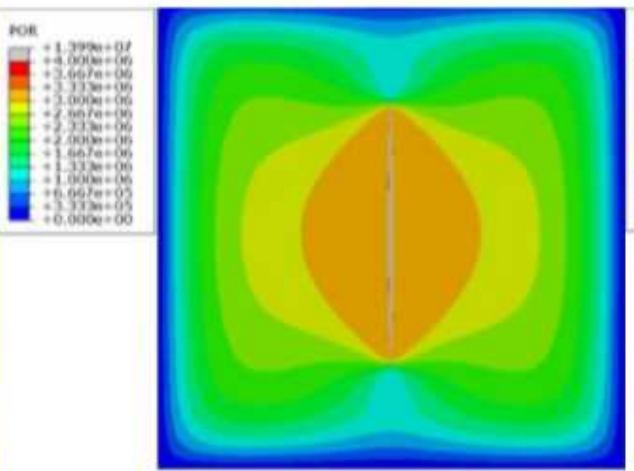

(b) Dilation angle $20^{\circ}$

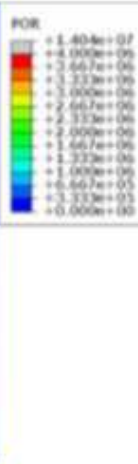

(c) Dilation angle $28^{\circ}$

\section{Figure 19}

Effect of dilation angle on pore pressure

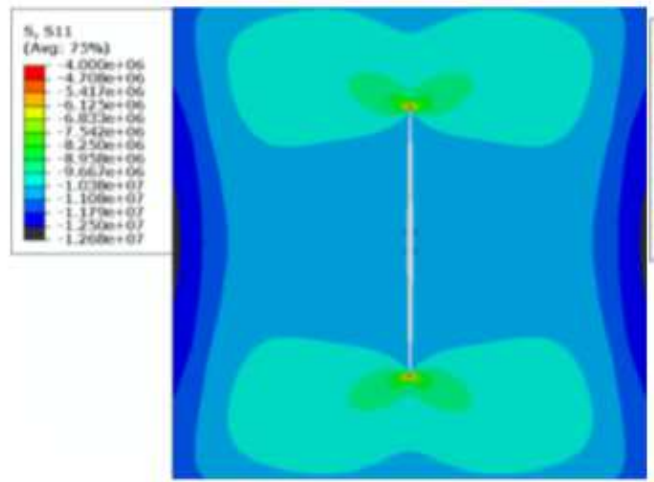

(a) Dilation angle $10^{\circ}$

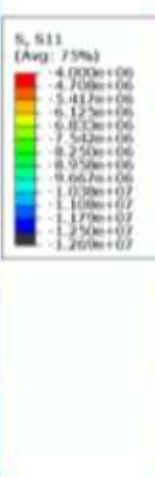

(b) Dilation angle $20^{\circ}$

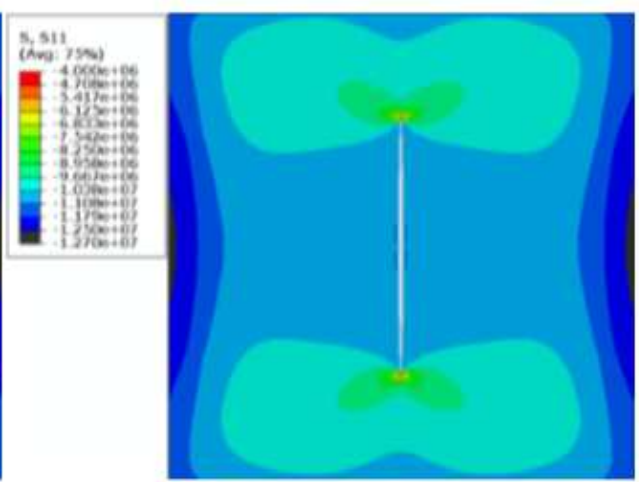

(c) Dilation angle $28^{\circ}$

Figure 20

Effect of dilation angle on stress on $\mathrm{x}$ direction 